\title{
Adenine protonation enables cyclic-di-GMP binding to cyclic-GAMP sensing riboswitches
}

\author{
HEIKO KELLER, ${ }^{1}$ A. KATHARINA WEICKHMANN, ${ }^{1}$ THOMAS BOCK, and JENS WÖHNERT \\ Institute for Molecular Biosciences and Center of Biomolecular Magnetic Resonance (BMRZ), Goethe University Frankfurt, \\ 60438 Frankfurt am Main, Germany
}

\begin{abstract}
In certain structural or functional contexts, RNA structures can contain protonated nucleotides. However, a direct role for stably protonated nucleotides in ligand binding and ligand recognition has not yet been demonstrated unambiguously. Previous X-ray structures of c-GAMP binding riboswitch aptamer domains in complex with their near-cognate ligand cdi-GMP suggest that an adenine of the riboswitch either forms two hydrogen bonds to a $G$ nucleotide of the ligand in the unusual enol tautomeric form or that the adenine in its N1 protonated form binds the G nucleotide of the ligand in its canonical keto tautomeric state. By using NMR spectroscopy we demonstrate that the c-GAMP riboswitches bind cdi-GMP using a stably protonated adenine in the ligand binding pocket. Thereby, we provide novel insights into the putative biological functions of protonated nucleotides in RNA, which in this case influence the ligand selectivity in a riboswitch.
\end{abstract}

Keywords: protonated adenine; riboswitch; c-di-GMP; c-GAMP; NMR; hydrogen bonds

\section{INTRODUCTION}

The $\mathrm{pK}_{\mathrm{a}}$ values of the nucleotide building blocks in RNA and DNA are far away from neutrality $(G, U \sim 9.2, A \sim 3.9$, $C \sim 4.2$ ) in unstructured nucleic acids (Saenger 1988). Watson-Crick base-pairing in double helical structural elements shifts these $\mathrm{pK}_{\mathrm{a}}$ values even further away from neutrality (Saenger 1988; Thaplyal and Bevilacqua 2014). Therefore, nucleotides in RNAs mostly adopt their canonical neutral protonation states and tautomeric forms. However, many RNAs incorporate non-Watson-Crick base pairs in their structures or adopt intricate tertiary structures. These structural environments can induce significant $\mathrm{pK}_{\mathrm{a}}$ shifts of RNA nucleotides toward neutrality leading to the occasional presence of nucleotides with altered protonation states in RNA structures. Very simple examples are $\mathrm{A}: \mathrm{C}$ mismatches embedded in regular $\mathrm{A}$-form double helical structural elements (e.g., Puglisi et al. 1990; Cai and Tinoco 1996; Huppler et al. 2002; Pechlaner et al. 2015). Adenine N1 protonation stabilizes these mismatches since two hydrogen bonds can be formed between $A+$ and $C$ resulting in a base pair with the same geometry as the classical G:U wobble pair. The $\mathrm{pK}_{\mathrm{a}}$ for the $\mathrm{A}$ in such base pairs is shifted by $\sim 3$ units and

\footnotetext{
${ }^{1}$ These authors contributed equally to this work and should be regarded as joint first authors.

Corresponding author: woehnert@bio.uni-frankfurt.de

Article is online at http://www.rnajournal.org/cgi/doi/10.1261/rna. 067470.118 .
}

can be as high as 8.2 in a particularly stable helical context (Wilcox and Bevilacqua 2013a,b). Similarly, N1 protonated A's are able to stabilize G:A mismatches in Watson-Crick helical contexts (Pan et al. 1999) as well as the parallel double helices formed by poly(rA) (Gleghorn et al. 2016). Protonated C's occur for instance in base triples and triple helices. Both protonated C's and A's have been observed in frame-shifting pseudoknots (e.g., Cornish et al. 2005; Houck-Loomis et al. 2011; Wilcox and Bevilacqua 2013a) and $\mathrm{pK}_{\mathrm{a}}$ values between 6.2 and 8.2 have been reported for these nucleotides. At physiological $\mathrm{pH}$ values these pseudoknots therefore exist as conformational ensembles containing protonated and deprotonated species. Thus, A or $C$ protonation might play a role in tuning conformational equilibria and thereby frameshifting efficiency. Of particular functional importance is the occurrence of nucleotides with shifted $\mathrm{pK}_{\mathrm{a}}$ values in the active site of ribozymes. The hammerhead, the hairpin, the VS, the twister and the pistol ribozyme all are reported to have a $\mathrm{G}$ with a $\mathrm{pK}_{\mathrm{a}}$ shifted toward neutrality in the active site (Wilcox et al. 2011; KathSchorr et al. 2012; Liu et al. 2014; Ren et al. 2014, 2016). There, it supposedly acts as the general base and activates

(C) 2018 Keller et al. This article is distributed exclusively by the RNA Society for the first 12 months after the full-issue publication date (see http://rnajournal.cshlp.org/site/misc/terms.xhtml). After 12 months, it is available under a Creative Commons License (Attribution-NonCommercial 4.0 International), as described at http://creativecommons.org/licenses/by-nc/4.0/. 
the attacking 2'-OH group in the first step of the phosphodiester cleavage reaction. For both the hairpin and the VS ribozyme an N1 protonated A supposedly is the general acid in the cleavage reaction (Rupert et al. 2002; Wilson et al. 2010; Kath-Schorr et al. 2012). For the twister and the pistol ribozyme an N3 protonated $A$ is suggested to play the same functional role (Ren et al. 2016; Wilson et al. 2016). A protonated $C$ is used as the general acid in the HDV ribozyme (Gong et al. 2007). However, in all cases described so far, the shifted $\mathrm{pK}_{\mathrm{a}}$ is near neutrality (7.0), suggesting that at physiologically relevant $\mathrm{pH}$ values these RNAs exist in an equilibrium with significant populations of protonated and deprotonated species. These equilibria are most likely functionally important for switching between active and inactive conformations and/or by allowing the catalytic base of a ribozyme to function as the catalytic acid in the reverse reaction and vice versa. Recently, examples for nucleotides in stable RNA tertiary structures with very strongly shifted $\mathrm{pK}_{\mathrm{a}}$ values $(>5 \mathrm{pH}$ units) were reported where the protonation enables these nucleotides to function as stabilizing building blocks of such structural elements (Wilcox and Bevilacqua 2013b; Gottstein-Schmidtke et al. 2014; Wolter et al. 2017). What has not been reported so far at least to our knowledge, however, is an example where a protonated nucleotide plays a direct role in ligand binding and recognition by a functional RNA.

However, a putative example for such an RNA with a protonated nucleotide directly binding to a ligand is represented by the riboswitches binding to the cyclic dinucleotide 3', 3'-cyclic-GMP-AMP (c-GAMP, Fig. 1A). c-GAMP has been discovered recently as a regulatory cyclic dinucleotide in bacteria and not much is known about its associated signaling pathways (Davies et al. 2012). In Geobacter species it regulates the expression of numerous genes involved in exoelectrogenesis by binding to c-GAMP
A
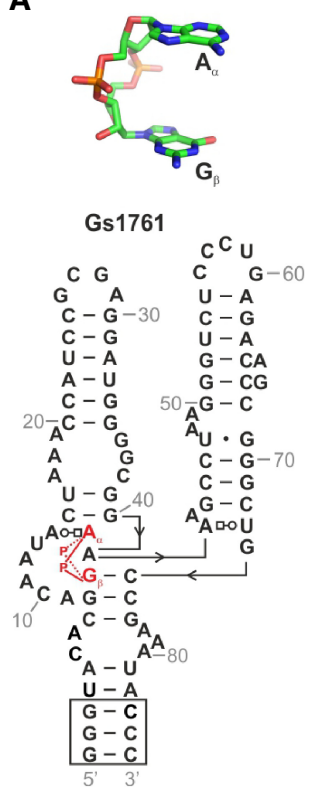

B
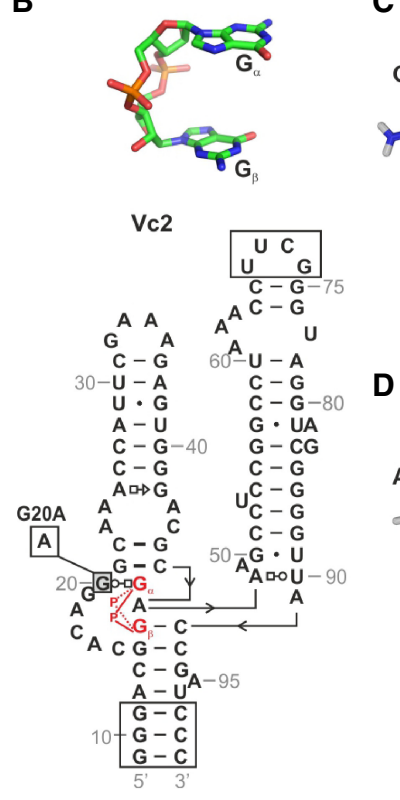

c
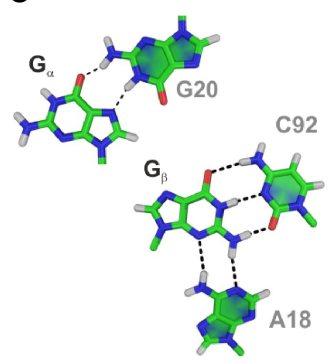

D

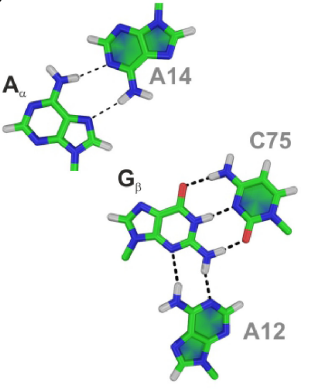

E

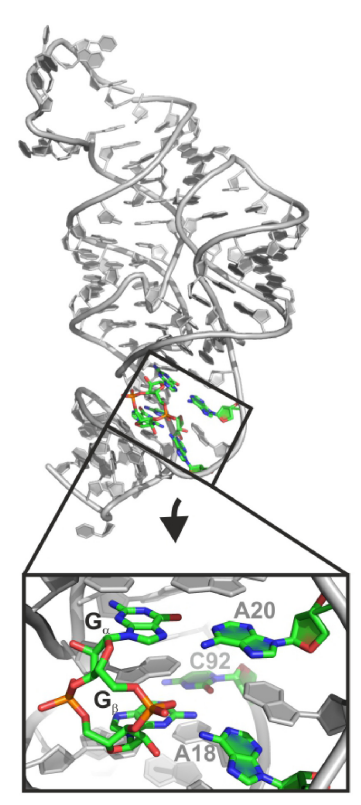

$\mathbf{F}$
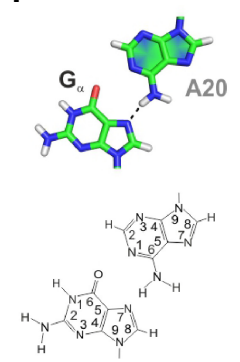

G

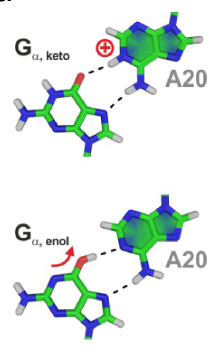

FIGURE 1. Ligand recognition by c-GAMP and c-di-GMP binding riboswitches. (A) Structure of $3^{\prime}, 3^{\prime}$-cyclic-GMP-AMP (c-GAMP, top) and secondary structure of a c-GAMP-binding riboswitch (bottom) from Geobacter sulfurreducens (Gs 1761, Ren et al. 2015). Nucleotides added to the terminus of the P1 stem in order to increase transcription efficiency and P1 stability in the NMR construct used in this study are boxed. The ligand is colored red. (B) Structure of c-di-GMP (top) and a c-di-GMP riboswitch from Vibrio cholerae (Vc2, Smith et al. 2009). Nucleotides added to the terminus of the P1 stem in order to increase transcription efficiency and an artificial stable UUCG tetraloop closing P3 in the NMR construct are boxed. The ligand is colored red. The position of the point mutation G20A that renders this riboswitch bispecific for c-GAMP and c-di-GMP is indicated by a shaded box. (C) Intermolecular base-pairing between the two ligand nucleotides $\mathrm{G}_{\alpha}$ and $\mathrm{G}_{\beta}$ and nucleotides of the c-di-GMP riboswitch as seen in the X-ray structure of the Vc2-RNA/c-di-GMP complex (PDB ID 3irw, Smith et al. 2009). (D) Intermolecular base-pairing between the two ligand nucleotides $A_{\alpha}$ and $G_{\beta}$ and nucleotides of the c-GAMP riboswitch as seen in the X-ray structure of the Gs1761-RNA/c-GAMP complex (PDB ID 4yaz, Ren et al. 2015). A14 here corresponds to G20 in the Vc2-riboswitch. (E) X-ray structure of the G20A-mutant of the Vc2 c-di-GMP-binding riboswitch bound to c-di-GMP (PDB ID 3mum, Smith et al. 2010). The ligand and riboswitch nucleotides involved directly in c-di-GMP binding are colored by atom type. The ligand-binding mode is shown as a close-up view. Nucleotides that recognize the ligand and the ligand itself are highlighted and shown as stick model. $(F)$ Interaction between $G_{\alpha}$ of the ligand and nucleotide A20 as seen in $E$. In order to facilitate the description of possible hydrogen bonding interaction in this base pair the atom numbering for both the $G_{a}$ and the $A 20$ is shown below. $(G)$ Two possible hydrogen-bonding patterns allowing the formation of two hydrogen bonds between $G_{\alpha}$ and $A 20$. A20 could be protonated at $\mathrm{N} 1$ (top) with $\mathrm{G}_{\alpha}$ adopting the standard keto tautomeric form or $\mathrm{G}_{\alpha}$ could occur as the 6-enol tautomer with $\mathrm{A} 20$ in the neutral nonprotonated state (bottom). 
riboswitches (Kellenberger et al. 2015; Nelson et al. 2015). These riboswitches are surprisingly similar in terms of sequence, secondary and tertiary structure to a previously described riboswitch class binding to cyclic-di-GMP (Fig. 1B) called GEMM-I (Sudarsan et al. 2008). The c-GAMP binding riboswitches are therefore designated as members of the GEMM-lb riboswitch class. A remarkable feature of the GEMM-I riboswitch aptamer domains is their generally high affinity for their cognate ligand c-diGMP with $K_{D}$ values sometimes in the picomolar range (Sudarsan et al. 2008; Smith et al. 2009). The high affinity of these riboswitches is most likely the consequence of the rather low intracellular concentrations of c-di-GMP found to be in the high nanomolar to low micromolar range depending on the organism and growth conditions (Kader et al. 2006; Simm et al. 2009) and a kinetic control of their activity (Wickiser et al. 2005). Notably, at these low concentrations c-di-GMP does not yet form kinetically stable G-quadruplex-like and other oligomeric structures that would compete with its signaling functions (Gentner et al. 2012) despite the presence of high intracellular concentrations of potassium ions. The intracellular concentrations of c-GAMP have not yet been systematically quantified in different organisms and growth conditions. However, in Geobacter sulfurreducens c-GAMP can reach concentration levels comparable to those of c-di-GMP under certain conditions (Kellenberger et al. 2015).

GEMM-I riboswitches bind their ligand c-di-GMP in a bipartite binding site (Kulshina et al. 2009; Smith et al. 2009,2010 ). The two guanine bases (designated $G_{\alpha}$ and $\mathrm{G}_{\beta}$ ) of the ligand are recognized differently (Fig. $1 \mathrm{C}$ ). The Hoogsteen-edge of $G_{\alpha}$ is recognized by the WatsonCrick edge of $\mathrm{G} 20$ from the riboswitch (nucleotide numbering in the RNA corresponds to the Vibrio cholera Vc2 sequence presented in Smith et al. 2009). Two hydrogen bonds are formed between the C6 carbonyl group of $\mathrm{G}_{\alpha}$ and the G20 amino group as well as between the N7 nitrogen of $G_{\alpha}$ and the $G 20$ imino group. $G_{\beta}$ forms a standard Watson-Crick base pair with $\mathrm{C92}$ of the riboswitch. In the c-GAMP-binding riboswitches G20 is replaced by an adenine nucleotide (A14 in the Geobacter sulfurreducens Gs1761 riboswitch, Fig. 1A). A $A_{\alpha}$ of c-GAMP now binds to A14 of the GEMM-lb riboswitch through a base-pairing interaction isosteric to the $G_{\alpha}: G$ base pair in the GEMM-I riboswitch (Fig. 1D, Ren et al. 2015, PDB ID 4yaz). The $A_{\alpha}$ amino group is hydrogen bonded to the $\mathrm{N} 1$ nitrogen of A14 and the $A_{\alpha}$ N7 nitrogen is hydrogen bonded to the A14 amino group (Fig. 1D). Surprisingly, the G20A mutation of the Vc2 GEMM-I riboswitch yields an RNA capable of binding to both c-di-GMP and to c-GAMP whereas the WT discriminates against c-GAMP (Smith et al. 2010; Kellenberger et al. 2013). Furthermore, a number of naturally occurring c-GAMP binding GEMM-lb riboswitches are apparently bispecific for c-di-GMP and c-GAMP (Kellenberger et al. 2015; Nelson et al. 2015). X-ray struc- tures of the Vc2 G20A mutant (Smith et al. 2010, PDB ID 3mum) and the Gs1761 c-GAMP riboswitch (Ren et al. 2015, PDB ID 4yb0) bound to c-di-GMP revealed a ligand recognition mode (Fig. 1E) with a hydrogen bond between the $\mathrm{N} 7$ nitrogen of $\mathrm{G}_{\alpha}$ and the $\mathrm{A} 20$ amino group (Fig. 1F) similar to what was observed for C-GAMP binding (Fig. 1D). Furthermore, in both of these structures there is a short distance (2.8 $\AA$ in pdb 3mum, Smith et al. 2010 and $3.0 \AA$ in pdb 4yb0, Ren et al. 2015) between the C6 carbonyl group of $\mathrm{G}_{\alpha}$ and the $\mathrm{N} 1$ nitrogen of $\mathrm{A} 20$ (Fig. 1F). When assuming standard protonation patterns for the nucleotides, both of these functional groups are hydrogen bond acceptors carrying a negative partial charge. Therefore, the observed close contact should be energetically unfavorable. However, if as suggested previously (Smith et al. 2010; Ren et al. 2015) A20 is protonated at the N1 nitrogen, it could form a stabilizing hydrogen bonding interaction with the $\mathrm{C} 6$ carbonyl group of $\mathrm{G}_{\alpha}$ (Fig. 1G, top). Alternatively, it was suggested (Ren et al. 2015) that $G_{\alpha}$ could adopt the enol tautomeric form with a hydroxyl group at C6. Then the C6 hydroxyl group could form a hydrogen bond to the $\mathrm{N} 1$ nitrogen of A20 (Fig. 1G, bottom). Both possibilities would be equally exciting because neither the direct participation of a protonated nucleotide in ligand binding in an RNA nor the stable induction of a rare tautomeric state for a standard nucleotide in an RNA structure have been demonstrated unequivocally. However, unusual tautomeric states in $\mathrm{G}: U$ mismatches are adopted transiently in low populations, as recently demonstrated by NMR spectroscopy (Kimsey et al. 2015). In addition, X-ray structures of near-cognate tRNAs bound to the decoding center of the ribosome and of mismatch-containing duplexes suggested that they play a role in miscoding (Demeshkina et al. 2012; Rozov et al. 2015, 2016; Rypniewski et al. 2016). However, $X$-ray structures with a resolution $>1 \AA$ do not allow the direct observation of hydrogen positions and thereby the unambiguous assignment of hydrogen bonding patterns in cases where the positions of the heavy atoms allow alternative hydrogen bonding patterns. For the complexes of c-diGMP bound to Vc2 G20A and Gs1761 the resolution is 2.9 $\AA$ (pdb 3mum) and $2.1 \AA$ (pdb 4yb0), respectively. On the other hand, solution NMR spectroscopy is a very useful tool for the direct unambiguous elucidation of hydrogen bonding patterns in nucleic acids (Dingley and Grzesiek 1998; Wöhnert et al. 1999; Duchardt-Ferner et al. 2011; Duchardt-Ferner and Wöhnert 2017). In particular, ${ }^{13} \mathrm{C}$ and ${ }^{15} \mathrm{~N}$ chemical shifts are faithful reporters of changes in protonation states (Legault and Pardi 1994, 1997). In favorable cases, NMR signals for protons at the protonation site can be detected directly (e.g., Macaya et al. 1991; Brodsky et al. 1998; Nixon et al. 2002; Cash et al. 2013; Gottstein-Schmidtke et al. 2014; Wolter et al. 2017). Some of the NMR methods for the identification of protonation events are applicable even for larger RNAs in cases where initial structural information from other methods is 
already available as in the case of the c-GAMP riboswitches and their complexes with c-di-GMP and c-GAMP.

Here we set out to delineate the hydrogen bonding patterns between c-di-GMP and the c-GAMP riboswitches by NMR. We find that an N1 protonated adenine nucleotide of the riboswitch forms a hydrogen bond to the guanine base $\left(G_{\alpha}\right)$ of the ligand in its standard neutral imino tautomeric state. The adenine N1 protonation is induced by cdi-GMP binding. The protonated state of the riboswitch in the c-di-GMP complex is persistent even at $\mathrm{pH}$ values above 8.3 and most likely limits the specificity of the cGAMP-binding riboswitches by allowing stable binding of c-di-GMP.

\section{RESULTS AND DISCUSSION}

The GEMM riboswitch variants with sizes of $>80$ nucleotides and their complex tertiary structures are challenging for NMR studies. In particular, NMR signal assignment strategies using the standard heteronuclear, multidimensional NMR approaches are no longer applicable for RNAs of this size with highly complex tertiary structures that are not amenable to "divide and conquer" approaches. Thus, our NMR studies had to rely on the available structural information from X-ray structures, the comparison of the NMR properties of different variants of the same riboswitch and chemical shift comparison in conjunction with base-type selective labeling. A particularly wellsuited starting point for our investigations was therefore the G20A-mutant of the c-di-GMP binding GEMM-I riboswitch from $V$. cholerae (Vc2, Fig. 1B). There are X-ray structures available for the WT-Vc2 riboswitch bound to c-di-GMP (PDB ID 3mxh, 2.3 A) as well as for the G20Amutant bound to c-di-GMP (PDB ID 3mum, $2.9 \AA$ ) and c-GAMP (PDB ID 4yb1, $2.1 \AA ̊$ ) revealing very similar overall structures (Smith et al. 2010; Ren et al. 2015). Therefore, the WT Vc2 riboswitch bound to c-di-GMP and the G20A-mutant bound to c-GAMP serve as reference states. Since they only differ by a single nucleotide from the G20A-mutant bound to c-di-GMP, they allow a meaningful comparison of their NMR spectra.

We initially characterized c-di-GMP and c-GAMP binding to the Vc2 WT riboswitch and the G20A mutant by 1D imino proton NMR spectra and ITC (Fig. 2). It should be noted that all NMR and ITC measurements reported in this study were carried out in buffers $(25$ or $50 \mathrm{mM}$ BisTris pH 6.5, $5 \mathrm{mM}$ magnesium acetate if not explicitly noted otherwise) completely lacking potassium ions. ${ }^{1} \mathrm{H}$ and ${ }^{31} \mathrm{P}-N M R$ experiments showed that in this buffer c-di-GMP does not form G-quadruplex or oligomeric structures (Supplemental Fig. S1) at the c-di-GMP concentrations needed for ITC or NMR experiments. In contrast, the presence of $25 \mathrm{mM}$ potassium phosphate or $25 \mathrm{mM}$ potassium phosphate and $250 \mathrm{mM}$ potassium chloride induced large changes in the NMR-spectra of free c-di-GMP
(Supplemental Fig. S1). These changes indicate the formation of G-quadruplex and other oligomeric structures at the c-di-GMP concentrations required for the NMR and ITC experiments $(>100 \mu \mathrm{M})$ in agreement with previous reports (Gentner et al. 2012). The formation of these structures would directly compete with c-di-GMP binding to RNA and thereby masking the effects of c-di-GMP binding in our experiments. Under in vivo conditions, however, these oligomeric c-di-GMP structures are apparently not relevant since the measured intracellular c-di-GMP concentrations are well below $100 \mu \mathrm{M}$ (Kader et al. 2006; Simm et al. 2009). At such low concentrations of c-diGMP no quadruplex formation and/or oligomerization was observed even in the presence of potassium ions (Gentner et al. 2012).

Both the Vc2 WT and the G20A RNA showed significant changes in their imino proton NMR spectra upon ligand addition in the presence of $5 \mathrm{mM} \mathrm{Mg}^{2+}$. The appearance of novel imino proton signals upon ligand addition suggested ligand-induced folding of the RNA in all cases. Importantly, the spectral changes observed upon addition of c-di-GMP or c-GAMP to the G20A-mutant are similar to the spectral changes observed for the WT-RNA upon addition of c-di-GMP (Fig. 2A) in agreement with a very similar ligand binding mode in all three cases. In contrast, the spectra of the WT-RNA in the presence of c-GAMP show a reduced number of imino proton signals compared to the other complexes in line with incomplete folding of the RNA upon binding c-GAMP. The WT-RNA binds cdi-GMP with a picomolar $K_{D}$ (Sudarsan et al. 2008; Smith et al. 2009, 2010). ITC measurements with c-GAMP showed that the affinity of the WT-RNA for this ligand is much lower, revealing a $K_{\mathrm{D}}$ of $10 \mu \mathrm{M}$ (Fig. 2B). In contrast, the G20A-mutant binds tightly to both c-di-GMP and cGAMP with $K_{D}$ values of 53 and $120 \mathrm{nM}$, respectively (Fig. 2B; Supplemental Table 1). Thus, as expected based on previous results, the G20A-mutant is bispecific and binds both ligands with similar affinity and a similar overall binding mode.

A very sensitive and well-established reporter for a putative protonation of adenines is their C2 chemical shift (Legault and Pardi 1994, 1997). The C2 chemical shifts for adenines are normally found in a range between 152 and 157 ppm. Upon protonation the C2 chemical shifts are observed 8-10 ppm upfield at 146-147 ppm. Thus, if c-di-GMP binding induces A20 protonation in the Vc2G20A mutant, an $\mathrm{H} 2 \mathrm{C} 2$ signal with an upfield C2 chemical shift should be found in a ${ }^{13} \mathrm{C}-\mathrm{HSOC}$ spectrum that would be absent in the spectra of both the c-di-GMP bound WTRNA as well as the c-GAMP bound G20A-mutant RNA. In order to reduce spectral crowding ${ }^{13} \mathrm{C}-\mathrm{HSQC}$-spectra were recorded for ${ }^{13} \mathrm{C}_{1}{ }^{15} \mathrm{~N}$-adenine labeled RNAs and unlabeled ligand. Thus, all other nucleotides of the RNA and the ligand are spectroscopically silent. A comparison of the ${ }^{13} \mathrm{C}$-HSOC-spectra of ${ }^{13} \mathrm{C}$-adenine labeled G20A 
A

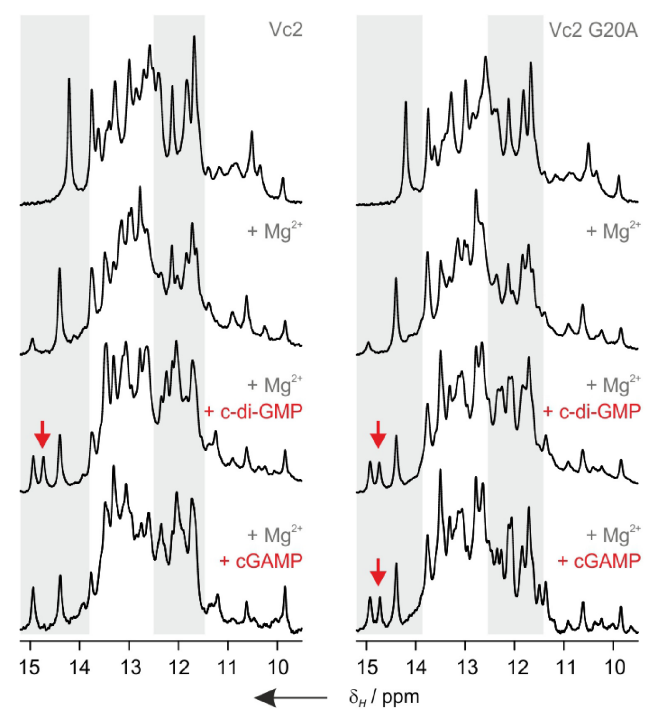

B

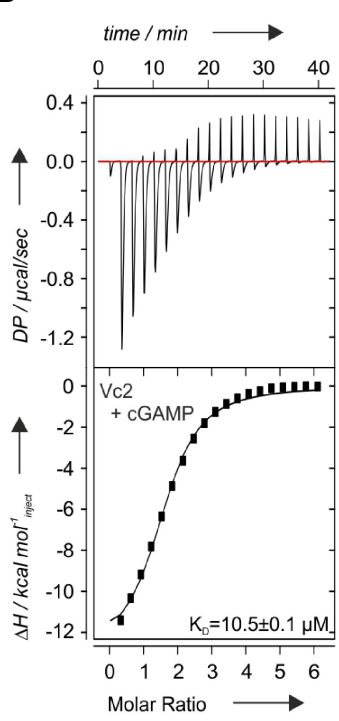

C

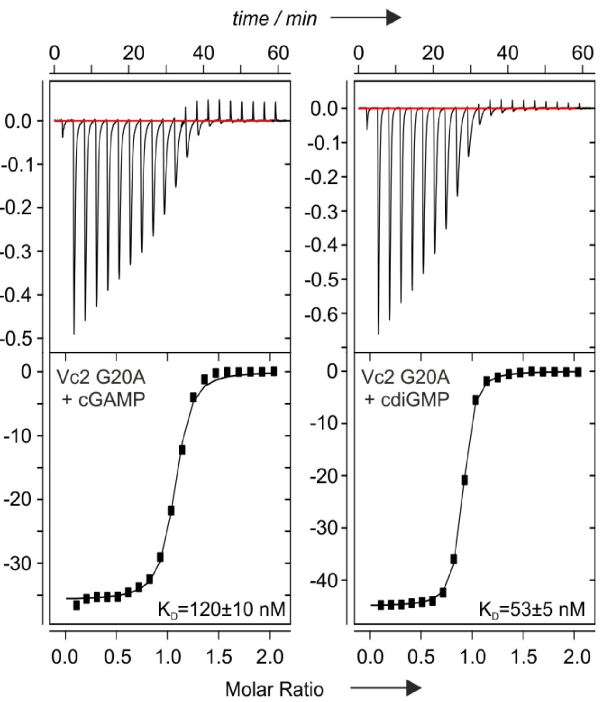

FIGURE 2. Ligand binding to the Vc2-WT and the Vc2-G20A-mutant riboswitch. (A) Comparison of the imino proton spectra of the Vc2-WT (left) and the Vc2-G20A-mutant (right) riboswitch RNA in the ligand-free state (top), in the presence of $5 \mathrm{mM} \mathrm{Mg}^{2+}$ (middle), in the presence of $5 \mathrm{mM}$ $\mathrm{Mg}^{2+}$ and c-di-GMP (middle) and in the presence of $5 \mathrm{mM} \mathrm{Mg}^{2+}$ and c-GAMP (bottom). Shaded areas highlight chemical shift regions with pronounced spectral changes. Note that the imino proton spectra of the G20A-mutant in the presence of c-di-GMP and c-GAMP are very similar to each other and to the spectra of the WT bound to c-di-GMP. In contrast, in the spectrum of the WT-riboswitch bound to c-GAMP imino proton signals are missing compared to those of the c-di-GMP complex and the mutant (red arrows) suggestive of incomplete folding. (B) ITC thermogram and fit for c-GAMP binding to the WT Vc2 riboswitch showing a $K_{\mathrm{D}}$ of only $10 \mu \mathrm{M}$. c-di-GMP is bound with a $K_{\mathrm{D}}$ in the picomolar range (Smith et al. 2009, 2010). (C) ITC thermograms and fits for c-GAMP (left) and c-di-GMP (right) binding to the G20A-mutant of the Vc2 riboswitch. C-GAMP is bound with a $K_{\mathrm{D}}$ of $120 \mathrm{nM}$ while c-di-GMP is bound with a $K_{\mathrm{D}}$ of $53 \mathrm{nM}$. All ITC-experiments shown here were carried out in a buffer containing $50 \mathrm{mM}$ Bis-Tris $\mathrm{pH} 6.5$ and $5 \mathrm{mM}$ magnesium acetate at $25^{\circ} \mathrm{C}$.

RNA in its free form and bound to c-di-GMP (Fig. 3A) reveals massive spectral differences. In particular, signal dispersion in the presence of c-di-GMP increases significantly in line with the expected ligand-induced folding of the RNA. Importantly, there is one signal present in the spectrum of the G20A-RNA/c-di-GMP complex with a chemical shift of $147.4 \mathrm{ppm}$ in the ${ }^{13} \mathrm{C}$-dimension and $8.3 \mathrm{ppm}$ in the ${ }^{1} \mathrm{H}$-dimension, respectively, which is not present in the free RNA and is a candidate for the $\mathrm{H} 2 \mathrm{C} 2$ signal of a protonated adenine. In the ${ }^{13} \mathrm{C}$-HSOC-spectrum of the WT RNA containing a $G$ at position 20 bound to c-di-GMP this signal is absent (Fig. 3B). This signal is also absent in the ${ }^{13} \mathrm{C}-\mathrm{HSOC}$ spectrum of the G2OA mutant RNA bound to c-GAMP where the nonprotonated nucleotide A20 forms hydrogen bonds to the Hoogsteen-edge of $A_{\alpha}$ of the ligand (Fig. 3C). A second signal that is only found in the ${ }^{13} \mathrm{C}-\mathrm{HSOC}$ spectrum of the G20A-RNA/c-di-GMP complex but not in those of the other two complexes appears at a chemical shift of $7.5 \mathrm{ppm}\left({ }^{1} \mathrm{H}\right)$ and $\sim 142 \mathrm{ppm}\left({ }^{13} \mathrm{C}\right)$. Comparison with spectra of other RNAs containing protonated adenines (Legault and Pardi 1997; Wolter et al. 2017) suggests that this signal might correspond to the $\mathrm{C} 8$ of a protonated adenine. Thus, the comparison of the ${ }^{13} \mathrm{C}$ HSOC spectra for the G20A-RNA/c-di-GMP complex with those of the WT-RNA bound to the same ligand and the G20A-RNA bound to c-GAMP shows that the former contains a protonated adenine not occurring in the latter two complexes. Due to the sequential and structural similarities of the three systems, A20 is the only logical candidate for the protonated adenine. Importantly, the signal corresponding to the protonated A20 in the G20A-RNA/ c-di-GMP complex is still observable with similar intensity and at the same position in ${ }^{13} \mathrm{C}-\mathrm{HSOC}$ spectra recorded at $\mathrm{pH} 8.3$, suggesting a stable protonation even at elevated pH (Fig. 3D). Unfortunately, the absence of chemical shift, line widths or intensity changes for the $\mathrm{A} 2 \mathrm{OH} 2 \mathrm{C} 2$ resonance upon increasing the $\mathrm{pH}$ from 6.5 to 8.3 prevented us from determining the $\mathrm{pK}_{\mathrm{a}}$ for $\mathrm{A} 20$ protonation in the G20A-RNA/c-di-GMP complex by pH titrations. We avoided increasing $\mathrm{pH}$ values above $\mathrm{pH} 8.3$ since under these conditions $G$ and $U$ nucleotides of the RNA, which are not in Watson-Crick base pairs, would start to become deprotonated to a significant amount $\left(\mathrm{pK}_{\mathrm{a}} \sim 9.2\right)$. Since such nucleotides are found in the direct vicinity of the binding site (Smith et al. 2009; Ren et al. 2015), chemical shift changes potentially observable at higher $\mathrm{pH}$ values could no longer be attributed to A20 deprotonation alone. Thus, we can only conclude that the $\mathrm{pK}_{\mathrm{a}}$ for $\mathrm{A} 20$ deprotonation in the complex must be significantly larger than 8.3.

The imino protons of protonated adenines are normally not directly observable at physiologically relevant $\mathrm{pH}$ due to fast exchange with the bulk solvent and/or rapid 


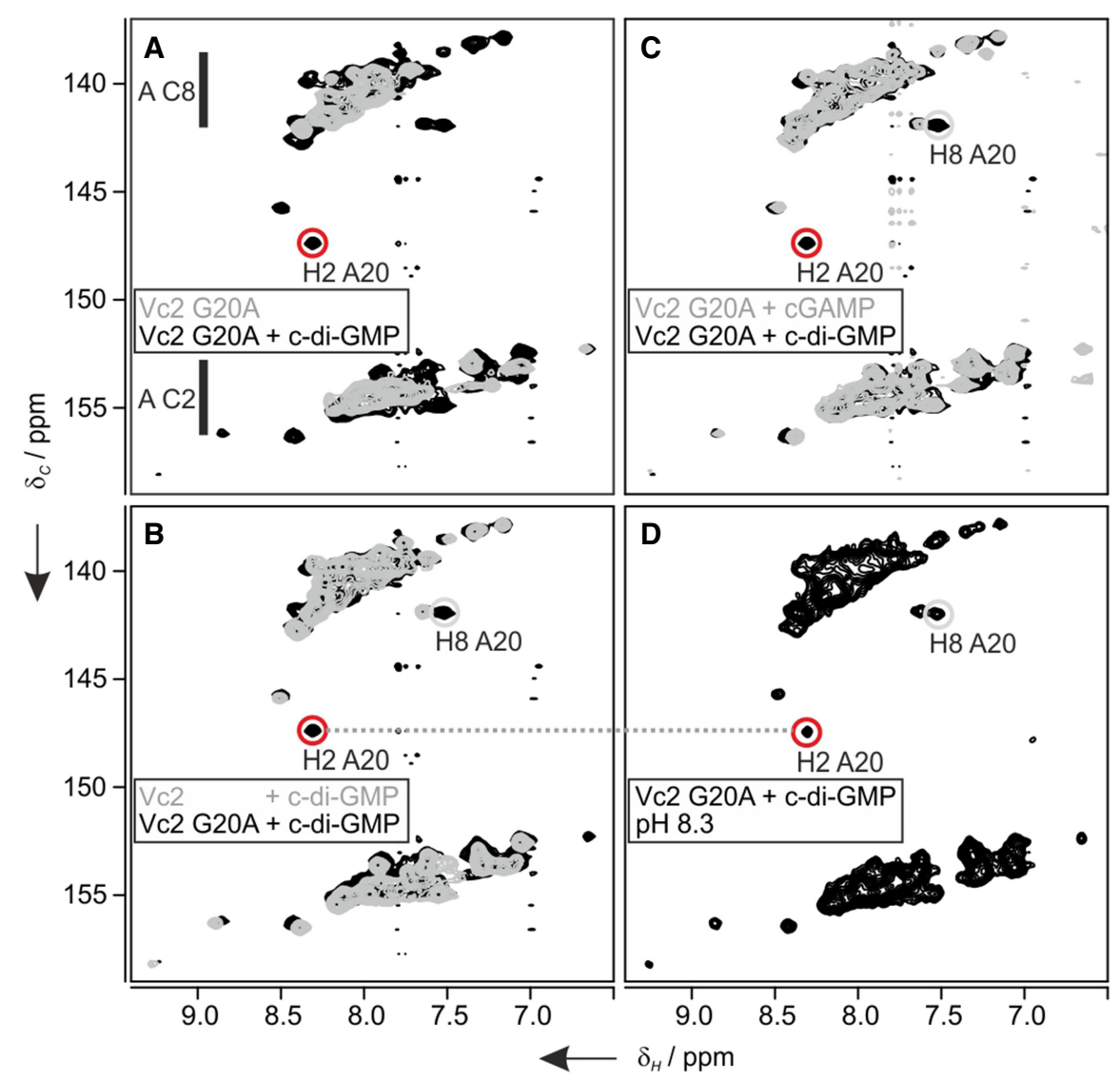

FIGURE 3. Evidence for a protonated $A 20$ in the complex of the G2OA-mutant Vc2 riboswitch bound to c-di-GMP. (A) Overlay of ${ }^{13} \mathrm{C}-\mathrm{HSOC}$ spectra of ${ }^{13} \mathrm{C},{ }^{15} \mathrm{~N}$-adenine labeled ligand-free G20A RNA (gray) and G20A RNA bound to c-di-GMP (black). Large spectral changes are observed as expected for ligand-induced RNA-folding. Importantly, a signal is observed with a ${ }^{13} \mathrm{C}$ chemical shift of $147.4 \mathrm{ppm}$ and a ${ }^{1} \mathrm{H}$ chemical shift of 8.3 ppm, respectively (red circle)— the chemical shift range associated with C2 carbon nuclei of protonated adenine nucleotides. The typical chemical shift ranges for adenine carbon nuclei are indicated by bars on the left side of the spectrum. (B) Overlay of the ${ }^{13} \mathrm{C}-\mathrm{HSOC}$-spectra of the G20Amutant (black) and the WT-RNA (gray) both bound to c-di-GMP. The H2C2 signal indicative of adenine protonation occurs only in the G20A-mutant. (C) Overlay of the ${ }^{13} \mathrm{C}$-HSOC-spectra of the G2OA-mutant RNA bound to c-di-GMP (black) or c-GAMP (gray). The H2C2 signal indicative of adenine protonation occurs only in the c-di-GMP complex. (D) ${ }^{13} \mathrm{C}-\mathrm{HSOC}$ spectrum recorded for the G20A-mutant bound to c-di-GMP recorded at $\mathrm{pH}$ 8.3. The $\mathrm{H} 2 \mathrm{C} 2$ signal typical for the protonated adenine unique to this complex is still present at high intensity (red circle) and has the same ${ }^{1} \mathrm{H}$ and ${ }^{13} \mathrm{C}$ chemical shifts as in the spectrum recorded at $\mathrm{pH} 6.5$.

opening of base-pairing interactions. The only instances of NMR observable adenine imino protons in nucleic acids to our knowledge were reported under conditions of either low $\mathrm{pH}$ or for RNAs where the protonated nucleotide was an integral part of the tertiary structure (Macaya et al. 1991; Wolter et al. 2017). A ${ }^{15} \mathrm{~N}-\mathrm{HSOC}$-spectrum recorded at $10^{\circ} \mathrm{C}$ with ${ }^{15} \mathrm{~N}$-adenine labeled G20A-mutant RNA bound to c-di-GMP showed a single adenine imino group resonance with chemical shifts of $\sim 13.7\left({ }^{1} \mathrm{H}\right)$ and $\sim 152.1\left({ }^{15} \mathrm{~N}\right)$ ppm, respectively (Fig. 4A). This imino resonance corresponds to the imino group of the protonated A20 that serves as a hydrogen bond donor to the C6 carbonyl group of the $\mathrm{G}_{\alpha}$ of the bound c-di-GMP. As expected, it is not observable in the G20A-RNA/c-GAMP complex (Fig. 4B) since in the c-GAMP complex the A20 adenine $\mathrm{N} 1$ nitrogen is not protonated and serves as a hydrogen bond acceptor for the $A_{\alpha}$ amino group of the
c-GAMP ligand (Fig. 1D). In a two-bond ${ }^{15} \mathrm{~N}-\mathrm{HSOC}$ spectrum the $\mathrm{H} 2$-proton at $8.3 \mathrm{ppm}$ corresponding to the protonated $\mathrm{A} 2 \mathrm{O}$ is connected to its $\mathrm{N} 3$ and the N1 nitrogen chemical shifts (Fig. 4C). The N1 chemical shift connected to the $\mathrm{H} 2$ proton of $\mathrm{A} 2 \mathrm{O}$ is the same as the one observed in the standard ${ }^{15} \mathrm{~N}-\mathrm{HSOC}$ and $\sim 60 \mathrm{ppm}$ upfield from the N1 nitrogen chemical shifts of the unprotonated adenine nucleotides as expected. Furthermore, temperature-dependent ${ }^{15} \mathrm{~N}$-HSOC-spectra show that the imino group signal is observable at temperatures up to $25^{\circ} \mathrm{C}$ (Fig. 4D). Thus, the protonation of $\mathrm{A} 20$ at N1 in the complex with c-di-GMP is very stable.

In a recent example of an RNA containing a $\mathrm{G}: \mathrm{A}^{+}$interaction with a geometry resembling the one of the $G_{\alpha}: A 20$ interaction, hydrogen bonding between the $\mathrm{G} C 6$ carbon$y l$ group and the $\mathrm{N} 1$ imino group of the protonated A lead to a pronounced downfield shift of the guanine $\mathrm{C} 6$ carbon 
A

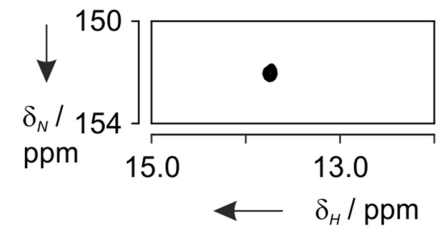

B

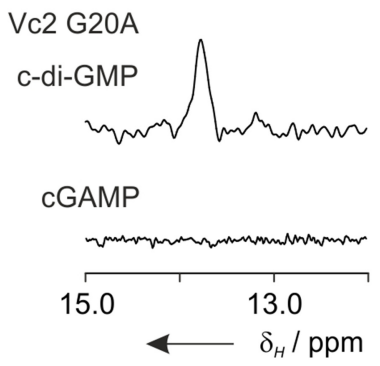

C

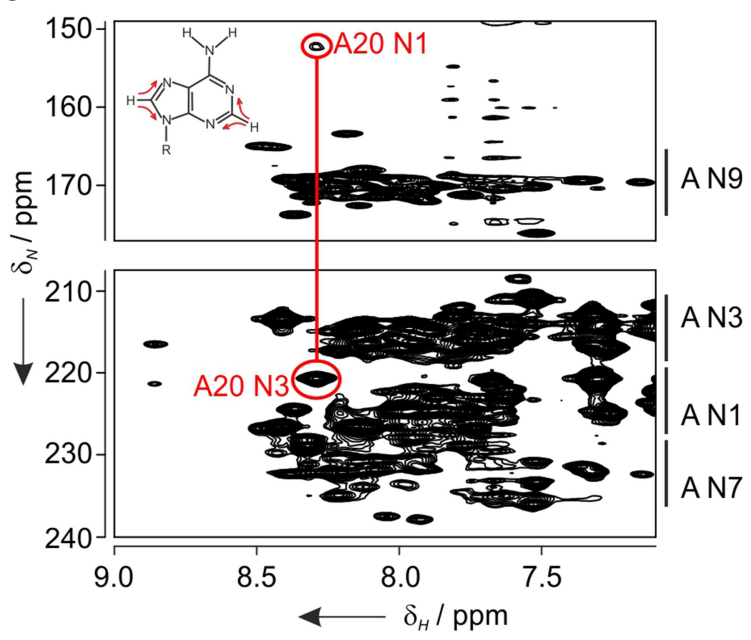

D

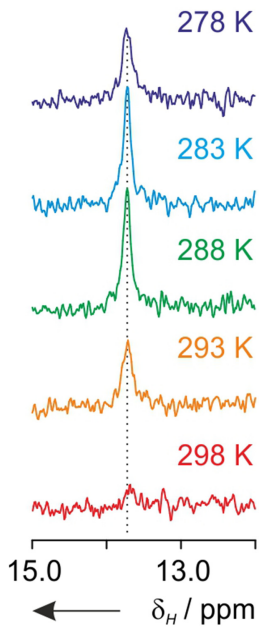

FIGURE 4. A20 is stably protonated at the $\mathrm{N} 1$ nitrogen in the G20A-mutant riboswitch in complex with c-di-GMP. (A) A $2 \mathrm{D}-{ }^{15} \mathrm{~N}-\mathrm{HSOC}$ spectrum recorded at $10^{\circ} \mathrm{C}$ for a sample containing ${ }^{15} \mathrm{~N}$-adenine labeled G20A-RNA bound to unlabeled c-di-GMP shows a single imino group signal. (B) A comparison of $1 \mathrm{D}-{ }^{15} \mathrm{~N}-\mathrm{HSOC}$ spectra at $10^{\circ} \mathrm{C}$ recorded with 256 scans in the c-di-GMP complex and 1024 scans in the c-GAMP complex show that while this imino proton signal is present in the c-di-GMP complex it is absent in the c-GAMP complex of the G20A mutant RNA. (C) A twobond 2D- ${ }^{15} \mathrm{~N}-\mathrm{HSOC}$ spectrum links the $\mathrm{H} 2$ proton of $\mathrm{A} 2 \mathrm{O}$ at $8.3 \mathrm{ppm}$ to the $\mathrm{N} 1$ and $\mathrm{N} 3$ nitrogens of the same nucleotide. An inset shows the magnetization transfer pathway for this experiment. The A20 N1 nitrogen chemical shift of $152.3 \mathrm{ppm}$ is 60 ppm upfield compared to the $\mathrm{N} 1$ chemical shifts for unprotonated adenines and is the same as the one observed for the imino group nitrogen in the standard ${ }^{15} \mathrm{~N}-\mathrm{HSOC}$ experiment. Vertical bars on the right side of the spectrum indicate the typical ${ }^{15} \mathrm{~N}$ chemical shift ranges for different types of nitrogen nuclei in adenine nucleotides. (D) The imino proton signal of $\mathrm{A}_{2} \mathrm{O}^{+}$is observable up to $25^{\circ} \mathrm{C}$ in $1 \mathrm{D}-{ }^{15} \mathrm{~N}$-HSOC -spectra at $\mathrm{pH} 6.5 \mathrm{suggesting}$ a stable protonation.

compared to all other guanine $\mathrm{C} 6$ resonances (Wolter et al. 2017). In order to measure the $C 6$ chemical shifts of c-diGMP bound to either WT-RNA or the G20A-mutant, we enzymatically prepared and purified ${ }^{13} \mathrm{C}$-labeled c-diGMP and measured ${ }^{13} \mathrm{C}-1 \mathrm{D}$-spectra of the labeled ligand bound to both RNAs in their unlabeled form (Fig. 5A). The $\mathrm{C} 6$ carbon of the c-di-GMP $\mathrm{G}_{\alpha}$ bound to the G20Amutant which interacts with the protonated $A 20$ is shifted downfield compared to the $\mathrm{G}_{\alpha} \mathrm{C} 6$ when bound to the WT RNA, where it interacts with the neutral G20 (Figs. $5 B, 1 G, C)$. On the other hand, the $G_{\beta} C 6$ chemical shift is very similar in both complexes, in agreement with a similar binding mode for $\mathrm{G}_{\beta}$ in both complexes.

The X-ray structures of the Vc2 and Vc2 G20A-complexes with their ligands revealed that $\mathrm{Mg}^{2+}$-ions played an integral role for RNA ligand interactions. In particular, both phosphate groups of the ligand are coordinated by $\mathrm{Mg}^{2+}$-ions. The closest distance between a bound $\mathrm{Mg}^{2+}$ and the $\mathrm{A} 20$ protonation site is $7.4 \AA$. Furthermore, comparison of the NMR-spectra of the free RNA in the absence and the presence of $\mathrm{Mg}^{2+}$ revealed differences in the imino proton region that are suggestive of a certain degree of $\mathrm{Mg}^{2+}$-induced structural preorganization of the RNA. In other RNAs containing protonated nucleotides, it was demonstrated that protonation and $\mathrm{Mg}^{2+}$-binding are anti-cooperative (Huppler et al. 2002; Wilcox and Bevilacqua 2013b). In contrast, in the HDV ribozyme the simultaneous protonation of $\mathrm{C} 41$ in a base triple and the binding of a structural $\mathrm{Mg}^{2+}$ ion cooperatively promote ribozyme folding and cleavage activity (Nakano and Bevilacqua 2007). In order to further characterize the interplay between $\mathrm{A} 20$ protonation and $\mathrm{Mg}^{2+}$-binding in the Vc2 G20A riboswitch/c-di-GMP complex, we compared ${ }^{1} \mathrm{H}-\mathrm{NMR}$ spectra and measured the ligand affinity at $\mathrm{pH} 6.5$ and 8.3 at different $\mathrm{Mg}^{2+}$ concentrations (Supplemental Fig. S2; Supplemental Table 2). At both $\mathrm{pH}$ values no ligand binding and no ligand-induced RNA folding was observable when the $\mathrm{Mg}^{2+}$ concentration was below $\sim 2 \mathrm{mM}$. At both $\mathrm{pH}$ values an increased $\mathrm{Mg}^{2+}$ concentration enhanced the affinity of the riboswitch for c-di-GMP. However, the c-di-GMP affinity is always higher at $\mathrm{pH} 6.5$ than at $\mathrm{pH}$ 8.3. Thus, both a low $\mathrm{pH}$ favoring $\mathrm{A} 20$ protonation as well as high $\mathrm{Mg}^{2+}$-concentrations favoring $\mathrm{Mg}^{2+}$-binding contribute positively to c-di-GMP binding and RNA-folding in this system.

We next investigated binding of both c-GAMP and c-diGMP to the Gs1761 riboswitch from Geobacter sulfurreducens (Kellenberger et al. 2015; Nelson et al. 2015). This riboswitch was described as being highly selective for cGAMP. Based on in-line-probing experiments, Hammond and coworkers (Kellenberger et al. 2015) reported $K_{D} S$ of this riboswitch for c-GAMP and c-di-GMP of 0.53 and $660 \mathrm{nM}$, respectively. Using ITC, Patel and coworkers (Ren et al. 2015) measured $K_{\mathrm{D}} \mathrm{s}$ of $70 \mathrm{nM}$ and $930 \mathrm{nM}$ for c-GAMP and c-di-GMP, respectively, in a buffer containing $50 \mathrm{mM}$ potassium acetate, $\mathrm{pH} 6.8,100 \mathrm{mM} \mathrm{KCl}$ and $20 \mathrm{mM}$ 
A

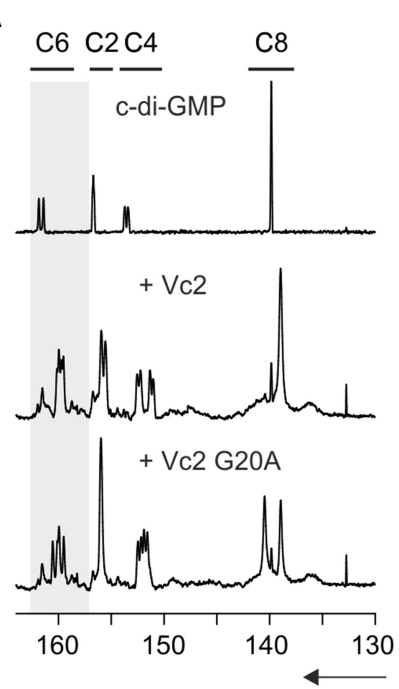

B

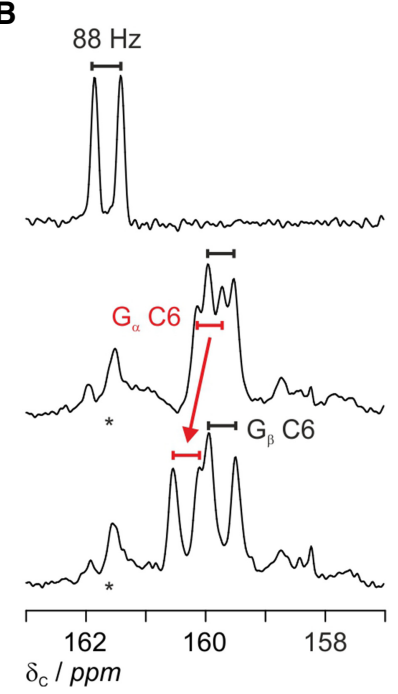

FIGURE 5. Adenine A20 N1 protonation induces a downfield shift of the $\mathrm{G}_{\alpha} \mathrm{C} 6$ carbon resonance. (A) Comparison of $1 \mathrm{D}-{ }^{13} \mathrm{C}$ spectra of ${ }^{13} \mathrm{C}^{15} \mathrm{~N}$-labeled c-di-GMP alone (top) and in complex with Vc2 (middle) or Vc2 G20A mutant RNA (bottom). The bars on top indicate typical chemical shift ranges for guanine carbon nuclei. The spectral region typical for C5 nuclei in guanines (115-120 ppm) is not shown. (B) Zoom of the spectral region that is shaded in $A$ to highlight the effect of the A2O protonation on the ligand C6 chemical shifts. Signals for c-di-GMP C6 carbon nuclei appear as doublets due to the $\mathrm{C}-\mathrm{C}$ scalar coupling with the $\mathrm{C} 5$ carbons $(88 \mathrm{~Hz})$. Adenine N1 protonation in the Vc2-G20A mutant leads to a downfield shift of the c-diGMP $G_{\alpha}$ C6 chemical shift compared to the Vc2-RNA (red) whereas the c-di-GMP $\mathrm{G}_{\beta} \mathrm{C} 6$ chemical shift is similar in both complexes (black). Natural abundance ${ }^{13} \mathrm{C}$-signals from the RNA are highlighted with an asterisk.

$\mathrm{MgCl}_{2}$ at an elevated temperature of $35^{\circ} \mathrm{C}$ probably in order to reduce c-di-GMP oligomerization. However, Patel and coworkers used an RNA sequence that accidentally differed by two point mutations from the WT-RNA (U72C, C73U) for X-ray structure determination and ITCexperiments (Fig. 1A; Supplemental Fig. S3). We initially used the same RNA sequence as Patel and coworkers with an additionally stabilized P1 stem (named Gs1761 throughout this paper) in our experiments (Fig. 1A). As expected from the earlier findings, our NMR titration experiments using 1D- ${ }^{1} \mathrm{H}$-imino proton spectra showed that both ligands bound to the Gs1761 riboswitch in the presence of $\mathrm{Mg}^{2+}$ and caused very similar spectral changes (Fig. 6A). Overall, the general quality of the proton spectra for the Gs1761 riboswitch complexes with both ligands is lower compared to the Vc2-derived RNAs. ITC-experiments with our Gs1761 construct under buffer conditions chosen to suppress intermolecular G-quadruplex formation by c-di-GMP ( $50 \mathrm{mM}$ Bis-Tris, pH 6.5, $5 \mathrm{mM} \mathrm{Mg}^{2+}$ acetate at $25^{\circ} \mathrm{C}$ ) showed that Gs1761 bound c-GAMP only approximately threefold tighter than c-di-GMP with $K_{\mathrm{D}}$ values of $290 \mathrm{nM}$ and $710 \mathrm{nM}$, respectively (Fig. 6B). Restoring the two point mutations to the wild-type se-

quence (Gs1761 WT) did not change the affinities of the riboswitch for c-GAMP (236 nM) and c-di-GMP (589 nM) significantly (Supplemental Fig. S3; Supplemental Table 1). When Bis-Tris is replaced by $50 \mathrm{mM}$ potassium phosphate in a buffer $\left(\mathrm{pH}\right.$ 6.5) containing $5 \mathrm{mM} \mathrm{Mg}^{2+}$ at $25^{\circ} \mathrm{C}$ the Gs1761 riboswitch binds c-GAMP with a $K_{D}$ of $302 \mathrm{nM}$ (Supplemental Fig. S4), which is very similar to the $K_{D}$ we measured in Bis-Tris buffer (292 nM). However, no binding of c-di-GMP to the RNA is detectable by ITC at $25^{\circ} \mathrm{C}$ (Supplemental Fig. S4), most likely due to the formation of competing G-quadruplex and oligomeric structures by c-di-GMP (Supplemental Fig. S1). Adding 250 mM potassium chloride to this buffer significantly enhances the affinity of the Gs1761 RNA for c-GAMP $\left(K_{D}=33 \mathrm{nM}\right.$, Supplemental Fig. S4) in agreement with the results of Patel and coworkers (Ren et al. 2015) but binding to c-di-GMP is again not detectable by ITC at $25^{\circ} \mathrm{C}$ (Supplemental Fig. S4).

The comparison of ${ }^{13} \mathrm{C}-\mathrm{HSQC}$ spectra for the ${ }^{13} \mathrm{C},{ }^{15} \mathrm{~N}$ adenine labeled Gs1761 RNA either in its free form or in the presence of c-di-GMP showed the appearance of only one signal with the chemical shift characteristics for a $\mathrm{H} 2 \mathrm{C} 2$-group of a protonated adenine with chemical shifts of $\sim 147.7 \mathrm{ppm}\left({ }^{13} \mathrm{C}\right)$ and $8.46 \mathrm{ppm}\left({ }^{1} \mathrm{H}, \mathrm{Fig} .6 \mathrm{C}\right)$. This signal is absent when the Gs1761 RNA is titrated with its cognate ligand c-GAMP (Fig. 6D). Thus, the appearance of this signal in the c-di-GMP complex therefore reports on the formation of the base-pairing interaction between $G_{\alpha}$ of the ligand and the protonated $A 14$ (equivalent to $A 20$ in the Vc2 G20A-mutant RNA) of the riboswitch.

Finally, we tested a c-GAMP riboswitch aptamer domain from Clostridium beijerinckii (Cbe 1-2) (Fig. 7A) for cGAMP and c-di-GMP binding that was described as being bispecific for both ligands (Nelson et al. 2015). In agreement with the previous observations for the other cGAMP binding riboswitch variants, both c-GAMP and cdi-GMP induced significant changes in the imino proton spectra of the RNA indicative of stable binding (Fig. 7B). ITC-experiments show that this RNA binds c-di-GMP with a lower $K_{\mathrm{D}}(30 \mathrm{nM})$ than c-GAMP $(463 \mathrm{nM})$ in $50 \mathrm{mM}$ BisTris buffer, $\mathrm{pH} 6.5,5 \mathrm{mM} \mathrm{Mg}^{2+}$ acetate at $25^{\circ} \mathrm{C}$ (Fig. 7C). The comparison of ${ }^{13} \mathrm{C}-\mathrm{HSOC}$ spectra for the ${ }^{13} \mathrm{C}{ }_{1}^{15} \mathrm{~N}$-adenine labeled Cbe 1-2 RNA either in its free form or in the presence of c-di-GMP again showed the appearance of one signal with the chemical shift characteristics for a H2C2-group of a protonated adenine (Fig. 7D). In analogy to the observations with the other riboswitches, this signal is absent when the Cbe 1-2 RNA is titrated with c-GAMP (Fig. 7E). Thus, Cbe 1-2 binds c-di-GMP via a protonated adenine residue as well. Protonation of the adenine nucleotide can therefore be regarded as a common feature for c-di-GMP binding in artificial riboswitch variants (Vc2 G20A), naturally occurring c-GAMP riboswitches with reportedly high specificity (Gs 1761) and those previously reported to be bispecific (Cbe 1-2). Thus, in these systems 


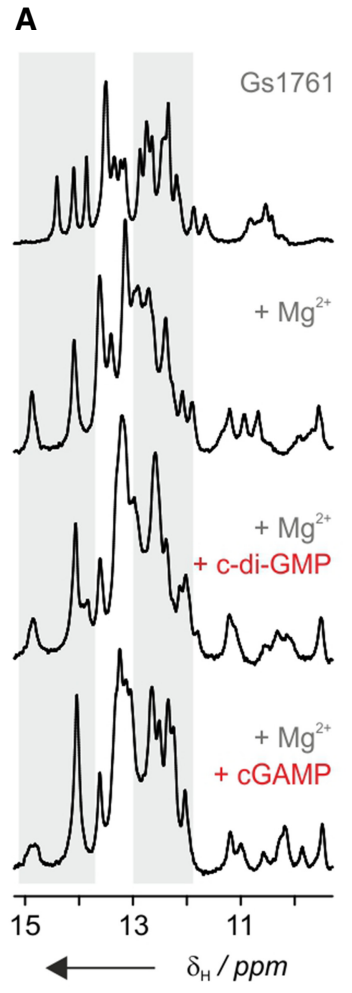

C
B

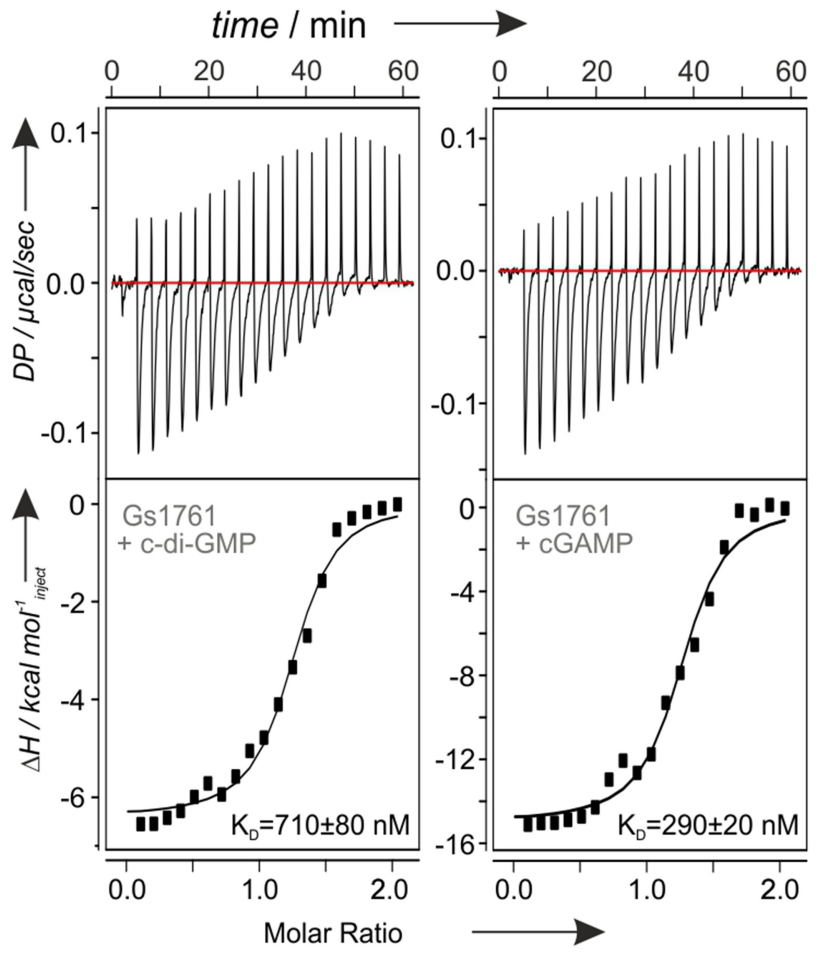

D

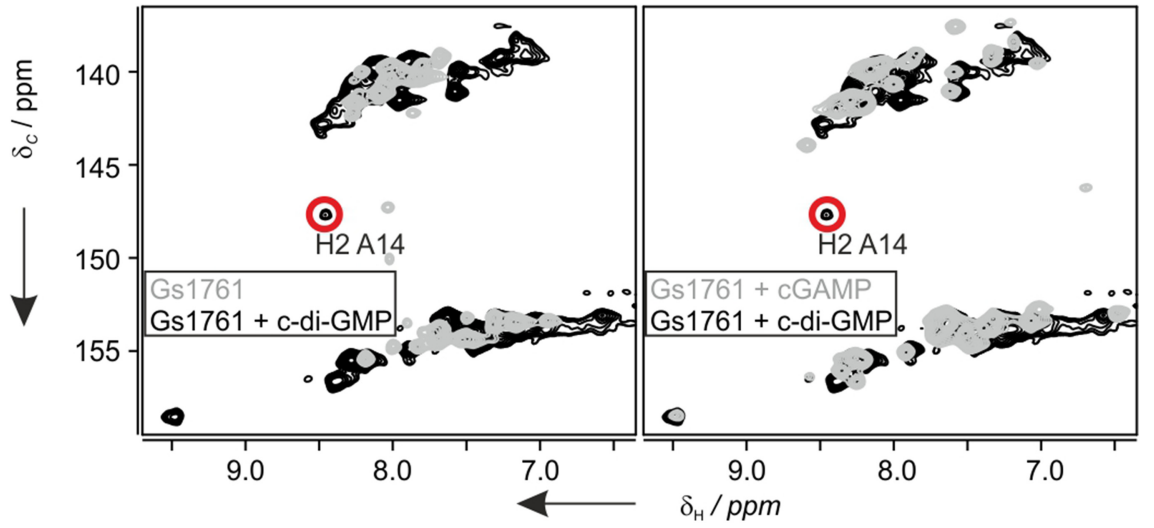

FIGURE 6. Ligand binding to the Gs1761 riboswitch and evidence for adenine protonation in the complex with c-di-GMP. (A) Imino proton spectra of the Gs1761 riboswitch RNA in the ligand-free state (top), in the presence of $\mathrm{Mg}^{2+}$ (middle), in the presence of $\mathrm{Mg}^{2+}$ and c-di-GMP (middle) and in the presence of $\mathrm{Mg}^{2+}$ and c-GAMP (bottom). Chemical shift regions with pronounced spectral changes are shaded in gray. (B) Representative ITC thermograms and fits for Gs1761 riboswitch RNA binding to c-di-GMP (left) and c-GAMP (right), respectively. (C) Overlay of ${ }^{13} \mathrm{C}$-HSOC spectra of ${ }^{13} \mathrm{C},{ }^{15} \mathrm{~N}$-adenine labeled Gs1761 riboswitch RNA in its ligand-free state (gray) or bound to c-di-GMP (black). RNA-folding is induced by ligand binding as observed by large spectral changes. Interestingly, one signal appears with a ${ }^{13} \mathrm{C}$ chemical shift of $147.7 \mathrm{ppm}$ and a ${ }^{1} \mathrm{H}$ chemical shift of $8.46 \mathrm{ppm}$ (red circle)—the chemical shift range associated with $\mathrm{C} 2$ carbon nuclei of N1 protonated adenine nucleotides. (D) Overlay of ${ }^{13} \mathrm{C}$-HSOC spectra of ${ }^{13} \mathrm{C}_{1}^{15} \mathrm{~N}$-adenine labeled Gs1761 riboswitch RNA bound to c-di-GMP (black) or c-GAMP (gray). The signal indicative of the adenine protonation is absent in the c-GAMP bound complex.

adenine protonation does not contribute to but probably rather limits the maximally achievable ligand selectivity since it supports c-di-GMP binding to c-GAMP riboswitches by allowing the formation of two hydrogen bonds between $G_{a}$ and the relevant riboswitch adenine residue. The significant differences in ligand affinities measured for the Gs1761 constructs with a natural P1 stem used by
Hammond and coworkers (Kellenberger et al. 2015) and for the Gs1761 variants used in this work and by Patel's group (Ren et al. 2015) with a strongly stabilized P1 stem suggest that the composition and stability of the P1 stem might contribute to ligand specificity by promoting cGAMP binding. Furthermore, high potassium ion concentrations apparently also support high affinity c-GAMP 
A

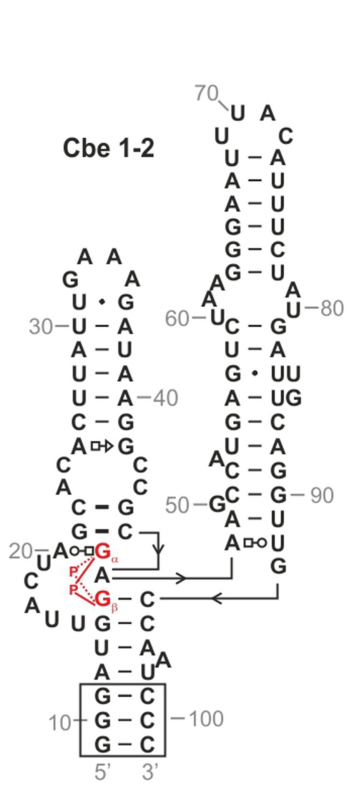

B

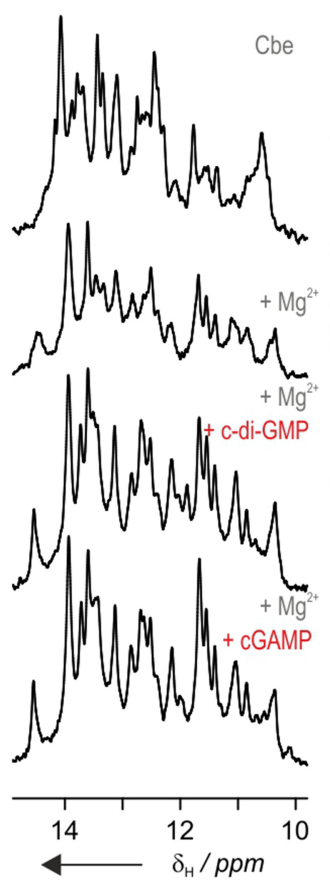

C

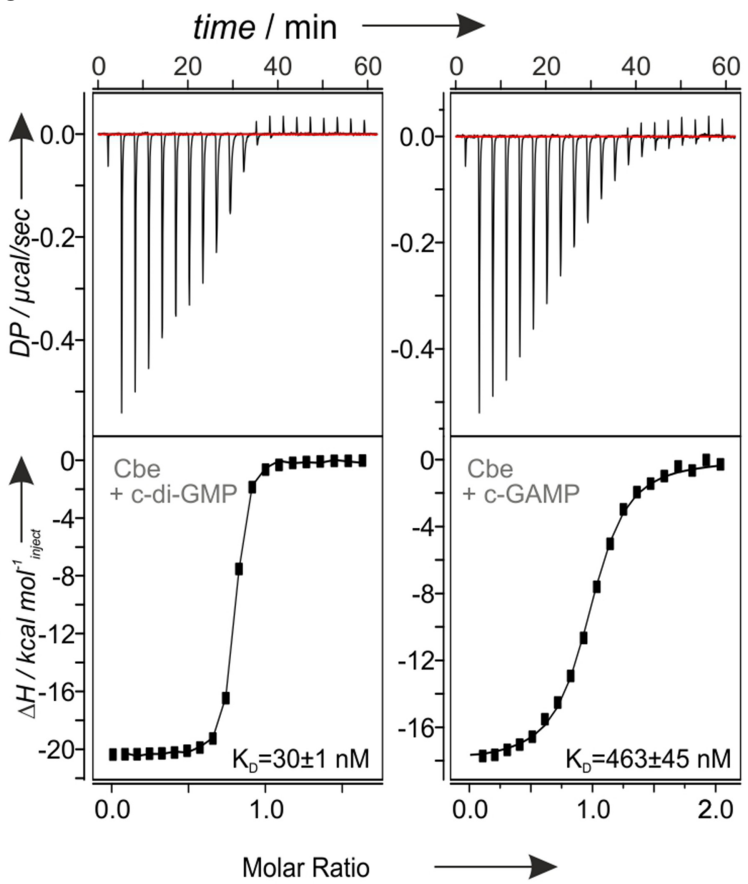

D

E

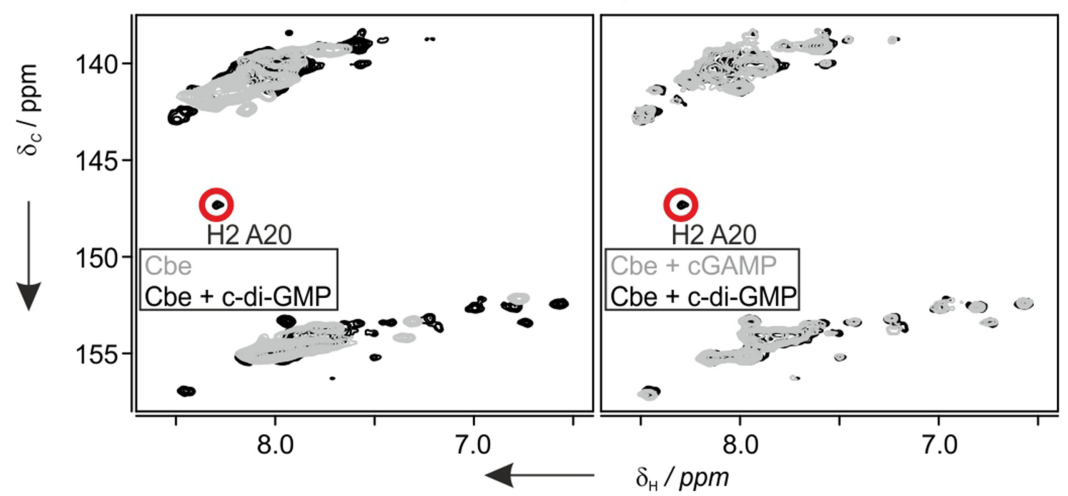

FIGURE 7. Ligand binding to the Clostridium beijerinckii (Cbe 1-2) riboswitch and evidence for adenine protonation in the complex with c-diGMP. (A) Secondary structure of the Cbe 1-2 riboswitch aptamer domain. (B) Imino proton spectra of the Cbe 1-2 riboswitch RNA in the ligandfree state (top), in the presence of $\mathrm{Mg}^{2+}$ (middle), in the presence of $\mathrm{Mg}^{2+}$ and c-di-GMP (middle) and in the presence of Mg ${ }^{2+}$ and c-GAMP (bottom). (C) Representative ITC thermograms and fits for Cbe 1-2 riboswitch RNA binding to c-di-GMP (left) and c-GAMP (right), respectively. The resulting $K_{D}$ values are given for both complexes. (D) Overlay of ${ }^{13} \mathrm{C}$-HSQC spectra of ${ }^{13} \mathrm{C}^{15} \mathrm{~N}$-adenine labeled Cbe $1-2$ riboswitch RNA in its ligand-free state (gray) or bound to c-di-GMP (black). The signal at a ${ }^{13} \mathrm{C}$ chemical shift of $147.3 \mathrm{ppm}$ and a ${ }^{1} \mathrm{H}$ chemical shift of $8.29 \mathrm{ppm}$ (red circle) appears in the chemical shift range that is associated with $\mathrm{C} 2$ carbon nuclei of N1 protonated adenine nucleotides. (E) Overlay of ${ }^{13} \mathrm{C}$ HSQC spectra of ${ }^{13} \mathrm{C}_{1}^{15} \mathrm{~N}$-adenine labeled Cbe 1-2 riboswitch RNA bound to c-di-GMP (black) or c-GAMP (gray). The signal indicative of the adenine protonation is present only in the c-di-GMP bound complex.

binding. However, a more complete analysis of the structural determinants for ligand specificity in this riboswitch class is beyond the scope of this work.

Overall, the experiments described here clarify the hydrogen bonding patterns between the GEMM-Ib riboswitches with their near-cognate ligand c-di-GMP. Interatomic distances between heavy atoms observed in X-ray crystallographic studies suggested that either a protonated A nucleotide of the riboswitch forms two hy- drogen bonds with $G_{\alpha}$ of the ligand in its canonical protonation state or that a standard $A$ forms hydrogen bonds to the $G_{\alpha}$ of the ligand assuming a rare tautomeric state. NMR spectroscopy unambiguously shows a protonated A of the riboswitch when bound to c-di-GMP and thereby establishes the c-di-GMP/GEMM-lb complex as the first example for an RNA where a protonated nucleotide is directly involved in ligand binding. Remarkably, the N1 protonated state of the $\mathrm{A}$ in this complex is persistent 
even at $\mathrm{pH}$ values well above neutrality. Thus, environmental $\mathrm{pH}$ changes apparently do not contribute to the modulation of ligand specificity of the GEMM-lb riboswitch. Instead, adenine protonation might be an important contribution to the widespread bispecific binding behavior for c-GAMP and c-di-GMP observed for members of this riboswitch class.

\section{MATERIALS AND METHODS}

\section{Templates for in vitro transcription}

We used PCR generated double-stranded DNA fragments or linearized plasmid DNA as template for T7 in vitro transcription. Overlapping oligonucleotides encoding a modified version of the c-di-GMP sensing riboswitch from Vibrio cholera (Vc2, Smith et al. 2009) and a mutant of this riboswitch harboring a guanine to adenine mutation at position 20 (Vc2 G20A) were used to generate double-stranded DNA fragments using PCR. pUC18-derived plasmids encoding the template sequences for $V_{c} 2, V_{c} 2$ G20A and modified versions of the cGAMP sensing riboswitches from Geobacter sulfurreducens (Gs1761, Ren et al. 2015) and Clostridium beijerinckii (Cbe 1-2, Nelson et al. 2015) were generated by Gibson cloning (Gibson et al. 2009).

\section{RNA preparation}

All RNAs were synthesized by run-off in vitro transcription using T7 RNA polymerase as previously described (Stoldt et al. 1998). Unlabeled, ${ }^{15} \mathrm{~N}$-adenine or ${ }^{13} \mathrm{C}_{1}{ }^{15} \mathrm{~N}$-adenine labeled $\mathrm{V}_{c} 2, \mathrm{~V}_{c} 2$ G20A, Gs1761, Gs1761WT as well as Cbe 1-2 were transcribed using Smal linearized plasmid DNA or PCR generated doublestranded DNA fragments as templates and purified by denaturing PAGE as previously described (Duchardt-Ferner et al. 2010). ${ }^{13} \mathrm{C},{ }^{15} \mathrm{~N}$ - and ${ }^{15} \mathrm{~N}$-labeled rNTPs were purchased commercially (Silantes).

RNAs were folded under conditions favoring monomeric hairpin structures in a low salt buffer ( $2.5 \mathrm{mM}$ Bis-Tris, $\mathrm{pH}$ 6.5) by denaturing at $70^{\circ} \mathrm{C}$ for $5 \mathrm{~min}$, rapid 10 -fold dilution with the same ice-cold buffer and subsequent annealing on ice. They were exchanged into $25 \mathrm{mM}$ Bis-Tris buffer, pH 6.5, $5 \mathrm{mM}$ magnesium acetate for NMR spectroscopy using ultracentrifugation devices (VivaSpin 2, MWC 3 kDa) and multiple cycles of concentration and dilution with NMR buffer. The RNAs in the final NMR samples were monomeric and homogeneous as judged from a native gel (Supplemental Fig. S5).

Unlabeled c-di-GMP and c-GAMP were purchased commercially as sodium salts (Sigma Aldrich) and dissolved in NMR buffer.

\section{Synthesis and purification of ${ }^{13} \mathrm{C}_{1}{ }^{15} \mathrm{~N}$-labeled c-di-GMP}

${ }^{13} \mathrm{C},{ }^{15} \mathrm{~N}$-labeled c-di-GMP was enzymatically synthesized as described in Rao et al. (2009) using the stand-alone GGEEF domain of the Thermotoga maritima diguanylate cyclase (TM1788) harboring the R158A mutation, except that we used ${ }^{13} \mathrm{C},{ }^{15} \mathrm{~N}$-labeled GTP as substrate for synthesis. Reactions were run at $45^{\circ} \mathrm{C}$ in TM1788 reaction buffer $(50 \mathrm{mM}$ Tris $/ \mathrm{HCl}, \mathrm{pH} 7.5,250 \mathrm{mM}$
$\mathrm{NaCl}, 20 \mathrm{mM} \mathrm{MgCl} 2,1 \mathrm{mM}$ DTT). The progress of the reaction was monitored by ${ }^{31} \mathrm{P}$ NMR and indicated complete conversion of GTP to c-di-GMP (Supplemental Fig. S6).

Magnesium pyrophosphate that precipitated during synthesis was separated by centrifugation. ${ }^{13} \mathrm{C},{ }^{15} \mathrm{~N}$-labeled c-di-GMP was purified from the reaction by phenol-chloroform extraction of the supernatant followed by ethanol precipitation of the aqueous phase. The pellet was dissolved in water and the concentration was determined spectroscopically using $26,100 \mathrm{M}^{-1} \mathrm{~cm}^{-1}$ as the extinction coefficient $\left(\varepsilon_{260}\right)$ for C-di-GMP. $1 \mathrm{D}-{ }^{1} \mathrm{H}, 1 \mathrm{D}-{ }^{13} \mathrm{C}$, $1 \mathrm{D}-{ }^{31} \mathrm{P}$, and $2 \mathrm{D}-{ }^{13} \mathrm{C}-\mathrm{HSOC}$-spectra of the product showed no impurities (Fig. 5A, top; Supplemental Fig. S6) and most importantly the absence of any remaining GTP. The molecular mass of the product was confirmed by high-resolution MALDI mass spectrometry.

\section{NMR spectroscopy}

NMR experiments were recorded on $600 \mathrm{MHz}$ Bruker AV, 600 $\mathrm{MHz}$ Bruker AVIII-HD, and $950 \mathrm{MHz}$ Bruker AVII NMR spectrometers, all equipped with $5 \mathrm{~mm}, z$-axis gradient ${ }^{1} \mathrm{H}\left[{ }^{13} \mathrm{C},{ }^{15} \mathrm{~N}\right]-\mathrm{TCl}$ cryogenic probes using standard pulse sequences (Fürtig et al. 2003). 1D imino proton spectra were recorded at $10^{\circ} \mathrm{C}$ using jump-return water suppression whereas ${ }^{13} \mathrm{C}-\mathrm{HSQC}$-spectra were recorded at $25^{\circ} \mathrm{C} .{ }^{13} \mathrm{C}-1 \mathrm{D}$ spectra were recorded on an $800 \mathrm{MHz}$ Bruker AV NMR spectrometer equipped with a $5 \mathrm{~mm}$, z-axis gradient ${ }^{13} \mathrm{C}_{1}^{15} \mathrm{~N}\left[{ }^{1} \mathrm{H}\right]$-TXO cryogenic probe at $25^{\circ} \mathrm{C}$. Unless stated otherwise, samples were measured in $25 \mathrm{mM}$ Bis-Tris ( $\mathrm{pH}$ 6.5), $5 \mathrm{mM}$ magnesium acetate containing $7.5 \% \mathrm{D}_{2} \mathrm{O}$. Spectra were processed and analyzed in TOPSPIN 3.2 (Bruker Biospin). RNA concentrations ranged from $100 \mu \mathrm{M}$ for unlabeled RNA, 300 $\mu \mathrm{M}$ for ${ }^{13} \mathrm{C},{ }^{15} \mathrm{~N}$-adenine labeled RNA to $900 \mu \mathrm{M}$ for ${ }^{15} \mathrm{~N}$-adenine labeled RNA. Samples with isotopically labeled RNA contained 1.2 equivalents of unlabeled c-di-GMP. The sample used for recording the $1 \mathrm{D}-{ }^{13} \mathrm{C}$-spectrum of ${ }^{13} \mathrm{C},{ }^{15} \mathrm{~N}$-labeled c-di-GMP bound to the unlabeled G20A-riboswitch contained $400 \mu \mathrm{M}$ c-di-GMP and 1.1 equivalents of RNA.

\section{Isothermal titration calorimetry (ITC)}

Unlabeled RNAs and both ligands (c-di-GMP, c-GAMP) were prepared in $50 \mathrm{mM}$ Bis-Tris ( $\mathrm{pH}$ 6.5) containing $5 \mathrm{mM}$ magnesium acetate, if not indicated otherwise. Additional experiments to test for the influence of potassium ions on the binding affinities were carried out in buffer containing $25 \mathrm{mM}$ potassium phosphate buffer, pH 6.5 and $5 \mathrm{mM}$ magnesium acetate with or without $250 \mathrm{mM}$ potassium chloride, respectively. ITC experiments at $\mathrm{pH} 8.3$ were carried out in $50 \mathrm{mM}$ Tris/ $\mathrm{HCl}$ buffer containing 0,2 , 5 , or $10 \mathrm{mM} \mathrm{Mg}^{2+}$. The ligand $(200-450 \mu \mathrm{M})$ was injected into a solution of 20-45 $\mu \mathrm{M}$ RNA. All measurements were performed at $25^{\circ} \mathrm{C}$ using a MicroCal iTC 200 instrument (Malvern Instruments). After an initial waiting time of $120 \mathrm{sec}$, the first injection of $0.2 \mu \mathrm{L}$ was followed by 19 serial injections of $2 \mu \mathrm{L}$, separated by intervals of 180-1440 sec. For each experiment, the reference power was set to $11 \mathrm{\mu cal}^{-1}$, stirring speed to $750 \mathrm{rpm}$ and the high feedback mode was selected for experiments with c-di-GMP, while for cGAMP experiments the low feedback mode was chosen. Three independent titrations were performed and the reported $K_{D}$ values are the average from these titrations. The thermograms were 
processed using Origin7.0 (OriginLab) assuming a one-site binding model. An overview of all binding parameters derived from the ITC measurements is given in Supplemental Tables 1 and 2.

\section{SUPPLEMENTAL MATERIAL}

Supplemental material is available for this article.

\section{ACKNOWLEDGMENTS}

This work was supported by the Center of Biomolecular Magnetic Resonance (BMRZ), the Deutsche Forschungsgemeinschaft (WO 901/6-1 as part of the special focus program SPP 1879 "Nucleotide Second Messenger Signaling in Bacteria" and project B10 of the CRC [SFB] 902 "Molecular Principles of RNA-based Regulation"). The ${ }^{13} \mathrm{C}^{15} \mathrm{~N}\left[{ }^{1} \mathrm{H}\right]-\mathrm{TXO}$ cryogenic probe for ${ }^{13} \mathrm{C}$ direct detection NMR experiments was obtained with support from the DFG (DFG INST 161/817-1 FUGG). We are grateful to members of the Wöhnert group for helpful discussions, to Kerstin Yacoub for help with sample preparations, to Elke Duchardt-Ferner for advice about NMR methods, and to ZhaoXun Liang for a gift of the plasmid for the expression of a c-diGMP synthase mutant from T. maritima.

Received May 26, 2018; accepted July 9, 2018.

\section{REFERENCES}

Brodsky AS, Erlacher HA, Williamson JR. 1998. NMR evidence for a base triple in the HIV-2 TAR C-G.C+ mutant-argininamide complex. Nucleic Acids Res 26: 1991-1995.

Cai Z, Tinoco IJr. 1996. Solution structure of loop A from the hairpin ribozyme from tobacco ringspot virus satellite. Biochemistry 35 : 6026-6036.

Cash DD, Cohen-Zontag O, Kim N-K, Shefer K, Brown Y, Ulyanov NB, Tzfati Y, Feigon J. 2013. Pyrimidine motif triple helix in the Kluyveromyces lactis telomerase RNA pseudoknot is essential for function in vivo. Proc Natl Acad Sci 110: 10970-10975.

Cornish PV, Hennig M, Giedroc DP. 2005. A loop 2 cytidine-stem 1 minor groove interaction as a positive determinant for pseudoknotstimulated -1 ribosomal frameshifting. Proc Natl Acad Sci 102: 12694-12699.

Davies BW, Bogard RW, Young TS, Mekalanos JJ. 2012. Coordinated regulation of accessory genetic elements produces cyclic di-nucleotides for V. cholerae virulence. Cell 149: 358-370.

Demeshkina N, Jenner L, Westhof E, Yusupov M, Yusupova G. 2012. A new understanding of the decoding principle on the ribosome. Nature 484: 256-259.

Dingley AJ, Grzesiek S. 1998. Direct observation of hydrogen bonds in nucleic acid base pairs by internucleotide ${ }^{2} J_{\mathrm{NN}}$ couplings. $J$ Am Chem Soc 120: 8293-8297.

Duchardt-Ferner E, Wöhnert J. 2017. NMR experiments for the rapid identification of $\mathrm{P}=\mathrm{O} \cdots \mathrm{H}-\mathrm{X}$ type hydrogen bonds in nucleic acids. J Biomol NMR 69: 101-110.

Duchardt-Ferner E, Weigand JE, Ohlenschläger O, Schmidtke SR, Suess B, Wöhnert J. 2010. Highly modular structure and ligand binding by conformational capture in a minimalistic riboswitch. Angew Chem Int Ed Engl 49: 6216-6219.

Duchardt-Ferner E, Ferner J, Wöhnert J. 2011. Rapid identification of noncanonical RNA structure elements by direct detection of $\mathrm{OH} \cdots \mathrm{O}=\mathrm{P}, \mathrm{NH} \cdots \mathrm{O}=\mathrm{P}$, and $\mathrm{NH} 2 \cdots \mathrm{O}=\mathrm{P}$ hydrogen bonds in solution NMR spectroscopy. Angew Chem Int Ed Engl 50: 7927-7930.
Fürtig B, Richter C, Wöhnert J, Schwalbe H. 2003. NMR spectroscopy of RNA. Chembiochem 4: 936-962.

Gentner M, Allan MG, Zaehringer F, Schirmer T, Grzesiek S. 2012. Oligomer formation of the bacterial second messenger c-diGMP: reaction rates and equilibrium constants indicate a monomeric state at physiological concentrations. J Am Chem Soc 134: 1019-1029.

Gibson DG, Young L, Chuang RY, Venter JC, Hutchison CAlll, Smith HO. 2009. Enzymatic assembly of DNA molecules up to several hundred kilobases. Nat Methods 6: 343-345.

Gleghorn ML, Zhao J, Turner DH, Maquat LE. 2016. Crystal structure of a poly $(\mathrm{r} A)$ staggered zipper at acidic $\mathrm{pH}$ : evidence that adenine N1 protonation mediates parallel double helix formation. Nucleic Acids Res 44: 8417-8424.

Gong B, Chen JH, Chase E, Chadalavada DM, Yajima R, Golden BL, Bevilacqua PC, Carey PR. 2007. Direct measurement of a pK(a) near neutrality for the catalytic cytosine in the genomic HDV ribozyme using Raman crystallography. J Am Chem Soc 129: 13335-13342.

Gottstein-Schmidtke SR, Duchardt-Ferner E, Weigand JE, Groher F, Suess B, Wöhnert J. 2014. Building a stable RNA U-turn with a protonated cytidine. RNA 20: 1163-1172.

Houck-Loomis B, Durney MA, Salguero C, Shankar N, Nagle JM, Goff SP, D'Souza VM. 2011. An equilibrium-dependent retroviral mRNA switch regulates translational recoding. Nature 480: 561-564.

Huppler A, Nikstad LJ, Allmann AM, Brow DA, Butcher SE. 2002. Metal binding and base ionization in the U6 RNA intramolecular stem-loop structure. Nat Struct Biol 9: 431-435.

Kader A, Simm R, Gerstel U, Morr M, Römling U. 2006. Hierarchical involvement of various GGDEF domain proteins in rdar morphotype development of Salmonella enterica serovar Typhimurium. Mol Microbiol 60: 602-616.

Kath-Schorr S, Wilson TJ, Li NS, Lu J, Piccirilli JA, Lilley DM. 2012. General acid-base catalysis mediated by nucleobases in the hairpin ribozyme. J Am Chem Soc 134: 16717-16724.

Kellenberger CA, Wilson SC, Sales-Lee J, Hammond MC. 2013. RNAbased fluorescent biosensors for live cell imaging of second messengers cyclic di-GMP and cyclic AMP-GMP. J Am Chem Soc 135: 4906-4609.

Kellenberger CA, Wilson SC, Hickey SF, Gonzalez TL, Su Y, Hallberg ZF, Brewer TF, lavarone AT, Carlson HK, Hsieh YF, et al. 2015. GEMM-I riboswitches from Geobacter sense the bacterial second messenger cyclic AMP-GMP. Proc Natl Acad Sci 112: 5383-5388.

Kimsey IJ, Petzold K, Sathyamoorthy B, Stein ZW, Al-Hashimi HM. 2015. Visualizing transient Watson-Crick-like mispairs in DNA and RNA duplexes. Nature 519: 315-320.

Kulshina N, Baird NJ, Ferré-D'Amaré AR. 2009. Recognition of the bacterial second messenger cyclic diguanylate by its cognate riboswitch. Nat Struct Mol Biol 16: 1212-1217.

Legault $P$, Pardi A. 1994. In situ probing of adenine protonation in RNA by ${ }^{13}$ C NMR. J Am Chem Soc 116: 8390-8391.

Legault P, Pardi A. 1997. Unusual dynamics and pKa shift at the active site of a lead-dependent ribozyme. J Am Chem Soc 119: 6621-6628.

Liu Y, Wilson TJ, McPhee SA, Lilley DM. 2014. Crystal structure and mechanistic investigation of the twister ribozyme. Nat Chem Biol 10: 739-744.

Macaya RF, Gilbert DE, Malek S, Sinsheimer JS, Feigon J. 1991. Structure and stability of X.G.C mismatches in the third strand of intramolecular triplexes. Science 254: 270-274.

Nakano S, Bevilacqua PC. 2007. Mechanistic characterization of the HDV genomic ribozyme: a mutant of the C41 motif provides 
insight into the positioning and thermodynamic linkage of metal ions and protons. Biochemistry 46: 3001-3012.

Nelson JW, Sudarsan N, Phillips GE, Stav S, Lünse CE, McCown PJ, Breaker RR. 2015. Control of bacterial exoelectrogenesis by CAMP-GMP. Proc Natl Acad Sci 112: 5389-5394.

Nixon PL, Rangan A, Kim YG, Rich A, Hoffman DW, Hennig M, Giedroc DP. 2002. Solution structure of a luteoviral P1-P2 frameshifting mRNA pseudoknot. J Mol Biol 322: 621-633.

Pan B, Mitra SN, Sundaralingam M. 1999. Crystal structure of an RNA 16-mer duplex R(GCAGAGUUAAAUCUGC) 2 with nonadjacent $\mathrm{G}$ (syn) $\cdot A^{+}$(anti) mispairs. Biochemistry 38: 2826-2831.

Pechlaner M, Donghi D, Zelenay V, Sigel RK. 2015. Protonation-dependent base flipping at neutral $\mathrm{pH}$ in the catalytic triad of a self-splicing bacterial group II intron. Angew Chem Int Ed Engl 54: 9687-9690.

Puglisi JD, Wyatt JR, Tinoco IJr. 1990. Solution conformation of an RNA hairpin loop. Biochemistry 29: 4215-4226.

Rao F, Pasunooti S, Ng Y, Zhuo W, Lim L, Liu AW, Liang ZX. 2009. Enzymatic synthesis of c-di-GMP using a thermophilic diguanylate cyclase. Anal Biochem 389: 138-142.

Ren A, Košutić M, Rajashankar KR, Frener M, Santner T, Westhof E, Micura R, Patel DJ. 2014. In-line alignment and $\mathrm{Mg}^{2+}$ coordination at the cleavage site of the env22 twister ribozyme. Nat Commun 5: 5534.

Ren A, Wang XC, Kellenberger CA, Rajashankar KR, Jones RA, Hammond MC, Patel DJ. 2015. Structural basis for molecular discrimination by a 3', 3'-cGAMP sensing riboswitch. Cell Rep 11: 1-12.

Ren A, Vušurović N, Gebetsberger J, Gao P, Juen M, Kreutz C, Micura R, Patel DJ. 2016. Pistol ribozyme adopts a pseudoknot fold facilitating site-specific in-line cleavage. Nat Chem Biol 12: 702-708.

Rozov A, Demeshkina N, Westhof E, Yusupov M, Yusupova G. 2015. Structural insights into the translational infidelity mechanism. Nat Commun 6: 7251.

Rozov A, Demeshkina N, Khusainov I, Westhof E, Yusupov M, Yusupova G. 2016. Novel base-pairing interactions at the tRNA wobble position crucial for accurate reading of the genetic code. Nat Commun 7: 10457.

Rupert PB, Massey AP, Sigurdsson ST, Ferré-D'Amaré AR. 2002. Transition state stabilization by a catalytic RNA. Science 298: 1421-1424.

Rypniewski W, Banaszak K, Kuliński T, Kiliszek A. 2016. Watson-Cricklike pairs in CCUG repeats: evidence for tautomeric shifts or protonation. RNA 22: 22-31.

Saenger W. 1988. Principles of nucleic acid structure. Springer, New York.

Simm R, Morr M, Remminghorst U, Andersson M, Römling U. 2009. Quantitative determination of cyclic diguanosine monophosphate concentrations in nucleotide extracts of bacteria by matrix-assisted laser desorption/ionization-time-of-flight mass spectrometry. Anal Biochem 386: 53-58.

Smith KD, Lipchock SV, Ames TD, Wang J, Breaker RR, Strobel SA. 2009. Structural basis of ligand binding by a c-di-GMP riboswitch. Nat Struct Mol Biol 16: 1218-1223.

Smith KD, Lipchock SV, Livingston AL, Shanahan CA, Strobel SA. 2010. Structural and biochemical determinants of ligand binding by the c-di-GMP riboswitch. Biochemistry 49: 7351-7359.

Stoldt M, Wöhnert J, Görlach M, Brown LR. 1998. The NMR structure of Escherichia coli ribosomal protein L25 shows homology to general stress proteins and glutaminyl-tRNA synthetases. EMBO J 17: 6377-6384.

Sudarsan N, Lee ER, Weinberg Z, Moy RH, Kim JN, Link KH, Breaker RR. 2008. Riboswitches in eubacteria sense the second messenger cyclic di-GMP. Science 321: 411-413.

Thaplyal P, Bevilacqua PC. 2014. Experimental approaches for measuring pKa's in RNA and DNA. Methods Enzymol 549: 189-219.

Wickiser JK, Winkler WC, Breaker RR, Crothers DM. 2005. The speed of RNA transcription and metabolite binding kinetics operate an FMN riboswitch. Mol Cell 18: 49-60.

Wilcox JL, Bevilacqua PC. 2013a. A simple fluorescence method for $\mathrm{pK}_{\mathrm{a}}$ determination in RNA and DNA reveals highly shifted $\mathrm{pK}_{\mathrm{a}}$ 's. J Am Chem Soc 135: 7390-7393.

Wilcox JL, Bevilacqua PC. 2013b. pKa shifting in double-stranded RNA is highly dependent upon nearest neighbors and bulge positioning. Biochemistry 52: 7470-7476.

Wilcox JL, Ahluwalia AK, Bevilacqua PC. 2011. Charged nucleobases and their potential for RNA catalysis. Acc Chem Res 44: 1270-1279.

Wilson TJ, Li NS, Lu J, Frederiksen JK, Piccirilli JA, Lilley DM. 2010. Nucleobase-mediated general acid-base catalysis in the Varkud satellite ribozyme. Proc Natl Acad Sci 107: 11751-11756.

Wilson TJ, Liu Y, Domnick C, Kath-Schorr S, Lilley DM. 2016. The novel chemical mechanism of the Twister ribozyme. J Am Chem Soc 138: 6151-6162.

Wöhnert J, Dingley AJ, Stoldt M, Görlach M, Grzesiek S, Brown LR. 1999. Direct identification of $\mathrm{NH} \cdots \mathrm{N}$ hydrogen bonds in non-canonical base pairs of RNA by NMR spectroscopy. Nucleic Acids Res 27: 3104-3110.

Wolter AC, Weickhmann AK, Nasiri AH, Hantke K, Wunderlich C, Kreutz C, Duchardt-Ferner E, Wöhnert J. 2017. A stably protonated adenine nucleotide with an extremely shifted pKa stabilizes the tertiary structure of a GTP-binding RNA-aptamer. Angew Chemie Int Ed Eng/ 56: 401-404. 

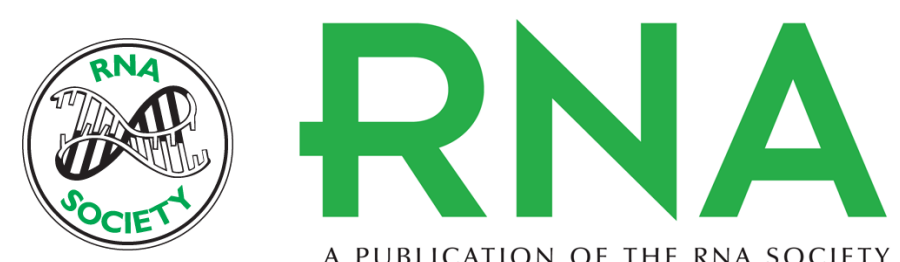

A PUBLICATION OF THE RNA SOCIETY

\section{Adenine protonation enables cyclic-di-GMP binding to cyclic-GAMP sensing riboswitches}

Heiko Keller, A. Katharina Weickhmann, Thomas Bock, et al.

RNA 2018 24: 1390-1402 originally published online July 13, 2018

Access the most recent version at doi:10.1261/rna.067470.118

\section{Supplemental http://rnajournal.cshlp.org/content/suppl/2018/07/13/rna.067470.118.DC1 Material}

References This article cites 56 articles, 11 of which can be accessed free at: http://rnajournal.cshlp.org/content/24/10/1390.full.html\#ref-list-1

Creative This article is distributed exclusively by the RNA Society for the first 12 months after the Commons License full-issue publication date (see http://rnajournal.cshlp.org/site/misc/terms.xhtml). After 12 months, it is available under a Creative Commons License (Attribution-NonCommercial 4.0 International), as described at http://creativecommons.org/licenses/by-nc/4.0/.

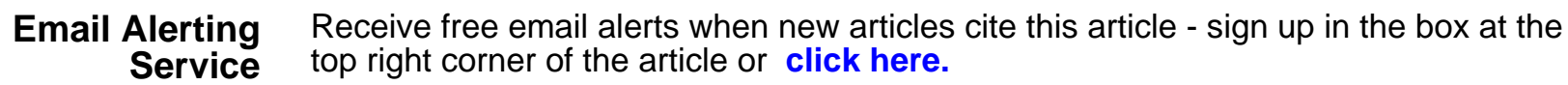

